\title{
Enhanced Accident Tolerant Fuels for LWRs - A Preliminary Systems Analysis
}

Gilles Youinou

R. Sonat Sen

September 2013

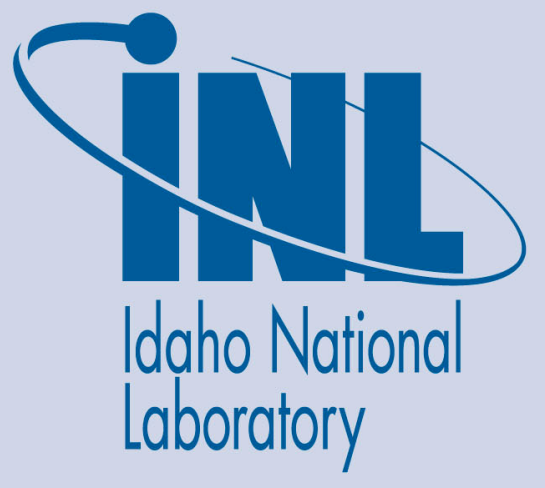

The INL is a U.S. Department of Energy National Laboratory operated by Battelle Energy Alliance 
INL/EXT-13-30211

FCRD-FCO-2013-000359

\title{
Enhanced Accident Tolerant Fuels for LWRs - A Preliminary Systems Analysis
}

\author{
Gilles Youinou \\ R. Sonat Sen
}

September 2013

\section{Idaho National Laboratory \\ Fuel Cycle Research \& Development \\ Idaho Falls, Idaho 83415}

http://www.inl.gov

Prepared for the

U.S. Department of Energy

Office of Nuclear Energy

Under DOE Idaho Operations Office

Contract DE-AC07-05ID14517 


\section{DISCLAIMER}

This information was prepared as an account of work sponsored by an agency of the U.S. Government. Neither the U.S. Government nor any agency thereof, nor any of their employees, makes any warranty, expressed or implied, or assumes any legal liability or responsibility for the accuracy, completeness, or usefulness, of any information, apparatus, product, or process disclosed, or represents that its use would not infringe privately owned rights. References herein to any specific commercial product, process, or service by trade name, trade mark, manufacturer, or otherwise, does not necessarily constitute or imply its endorsement, recommendation, or favoring by the U.S. Government or any agency thereof. The views and opinions of authors expressed herein do not necessarily state or reflect those of the U.S. Government or any agency thereof. 


\section{SUMMARY}

The severe accident at Fukushima Daiichi nuclear plants illustrates the need for continuous improvements through developing and implementing technologies that contribute to safe, reliable and cost-effective operation of the nuclear fleet. Development of enhanced accident tolerant fuel contributes to this effort. These fuels, in comparison with the standard zircaloy - $\mathrm{UO}_{2}$ system currently used by the LWR industry, should be designed such that they tolerate loss of active cooling in the core for a longer time period (depending on the LWR system and accident scenario) while maintaining or improving the fuel performance during normal operations, operational transients, and design-basis events.

This report presents a preliminary systems analysis related to most of these concepts. The potential impacts of these innovative LWR fuels on the front-end of the fuel cycle, on the reactor operation and on the back-end of the fuel cycle are succinctly described without having the pretension of being exhaustive. Since the design of these various concepts is still a work in progress, this analysis can only be preliminary and could be updated as the designs converge on their respective final version. 


\section{CONTENTS}

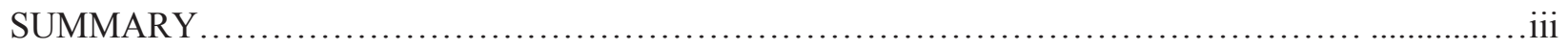

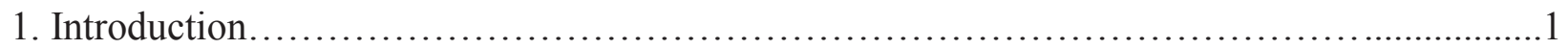

2. Fully Ceramic Microencapsulated Fuel................................................

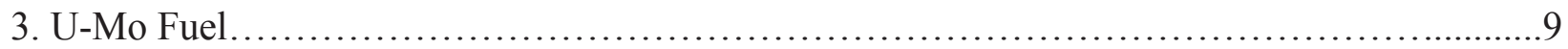

4. UN Fuel........................................................................ 12

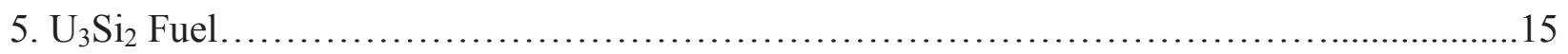

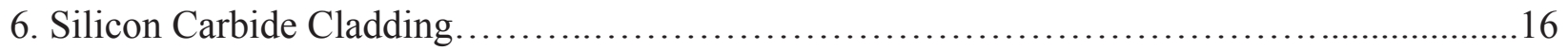

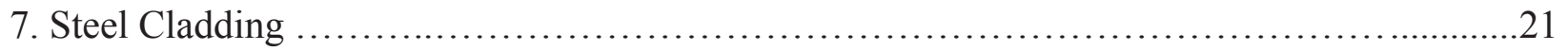

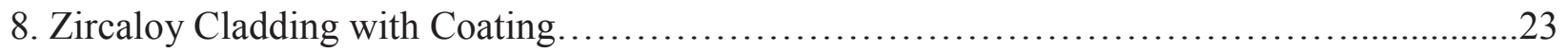

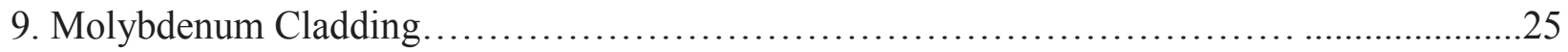

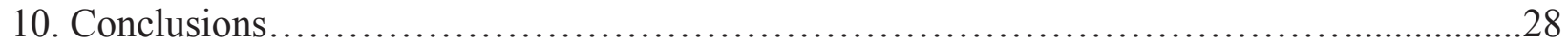

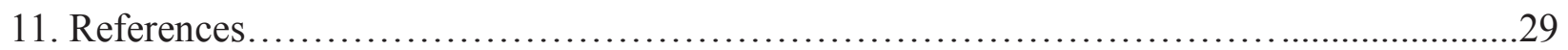

Appendix A. Estimation of the C14 production by $(n, p)$ reactiom on N14 in an FCM fuelled PWR using UN fuel kernel with natural nitrogen..........................................32

Appendix B. Estimation of the C14 production by $(n, p)$ reactiom on N14 in a PWR using UN

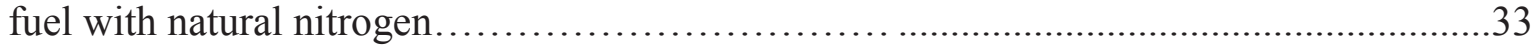

Appendix C. Using molybdenum depleted in Mo-95 in UMo fuels..........................34 


\section{FIGURES}

Figure 2.1.Illustration of the FCM fuel concept $\ldots$

Figure 3.1 Illustration of the annular U-Mo fuel concept $\ldots$

Figure 8.1 Illustration of the coating concept

Figure 9.1 Illustration of a possible molybdenum-based cladding concept _................................

\section{TABLES}

Table 1.1 Accident Tolerant Fuel Concepts under Consideration _.......................................... 2

Table 2.1 Cost of a $\mathrm{UO}_{2}$ assembly in an AP-1000 core $\quad 8$

Table 6.1 Comparison between the cost of LWR oxide and SiC clad LWR assemblies in an AP-1000 core

Table 8.1 Fuel enrichment that matches the reference cycle length as a function of coating composition and thickness 



\section{FUEL CYCLE OPTIONS CAMPAIGN}

\section{INTRODUCTION}

Fuels with enhanced accident tolerance, in comparison with the standard zircaloy- $\mathrm{UO}_{2}$ system currently used by the LWR industry, should be designed such that they tolerate loss of active cooling in the core for a longer time period while maintaining or improving the fuel performance during normal operations, operational transients, and design-basis events. To mitigate or reduce the consequences of fuel failure at elevated temperatures with steam exposures, the following attributes and issues must be considered [1.1]:

- Improved Reaction Kinetics with Steam. The issue is rapid oxidation of the cladding and the associated exothermic reaction, which increases the cladding temperature even further during the oxidation phase.

- Slower Hydrogen Generation Rate. The issue is the generation of free hydrogen brought about by the rapid oxidation of the cladding. Another related issue is the diffusion of free hydrogen into the unoxidized portion of the cladding, resulting in enhanced embrittlement.

- Improved Cladding Thermo-Mechanical Properties. When exposed to steam at high temperatures, there are multiple issues that need to be considered, including cladding failure (i.e., breach) and/or melting, thermal-shock resistance during emergency coolant injection (reflood), and ballooning (loss of coolable geometry).

- Improved Fuel Thermo-Mechanical Properties. The issues are fuel melting and relocation, as well as fuel dispersion into the coolant. In addition, fuel-cladding chemical interactions and fuel cladding mechanical interactions, as well as the stored heat during normal operations before the initiation of the accident, are attributes associated with the accident tolerance of a given fuel.

- Reduced Fission Product Release. The main issue for cladding failure is retention of the fission products within the vessel to minimize releases to the environment. This includes both gaseous and solid fission products. While total retention may not be possible, even partial retention (especially for highly mobile fission products) would be a substantial improvement over the current fuel and cladding.

The Advanced Fuels Campaign, under the purview of its focus area on next generation LWR fuels with enhanced performance and safety, is supporting the development of a range of Enhanced Accident Tolerant Fuel concepts. Eight Development Teams are currently active [1.2]:

1) Two campaign directed efforts. The development of the Fully Ceramic Micro-encapsulated (FCM) fuel concept is led by Oak Ridge National Laboratory (ORNL). The development of the LWR U- 
Mo fuel concept is led by Pacific Northwest National Laboratory (PNNL). In addition, Los Alamos National Laboratory is a key contributor in the development of advanced, corrosion resistant metallic alloys that could be used as cladding in a number of other ATF concepts.

2) Three Funding Opportunity Announcement (FOA) efforts. These FOA consortia are industry-led teams that also include DOE laboratories and universities as partners. The three FOA teams are led by Westinghouse, AREVA, and General Electric.

3) Three Integrated Research Proposal (IRP) efforts. These IRP consortia are university-led teams involving multiple universities, and in some cases industry entities and/or DOE laboratories, as partners. The three IRP teams are led by the University of Illinois, University of Tennessee, and Georgia Institute of Technology. It is important to note that the Georgia Institute of Technology effort is focused on developing an accident tolerant reactor concept that would incorporate an accident tolerant fuel that is developed by one of the other R\&D teams.

The table below summarizes the various concepts under consideration.

Table 1.1. Enhanced Accident Tolerant Fuel Concepts under Consideration [1.2]

\begin{tabular}{|c|c|c|c|}
\hline $\begin{array}{l}\text { ATF } \\
\text { Development } \\
\text { Lead } \\
\end{array}$ & Fuel & Cladding & Coating \\
\hline ORNL & $\begin{array}{l}\mathrm{FCM} \\
\mathrm{UO}_{2}\end{array}$ & $\begin{array}{c}\text { Zircaloy } \\
\text { FeCrAl } \\
\text { SiC }\end{array}$ & $\mathrm{n} / \mathrm{a}$ \\
\hline PNNL & $\begin{array}{l}\text { U-10Mo } \\
\text { U-7Mo }\end{array}$ & MA-956 & $\mathrm{n} / \mathrm{a}$ \\
\hline LANL & $\mathrm{UO}_{2}$ & Mo & $\mathrm{n} / \mathrm{a}$ \\
\hline Westinghouse & $\begin{array}{c}\mathrm{UN}+\mathrm{U}_{3} \mathrm{Si}_{2} \\
\mathrm{U}_{3} \mathrm{Si}_{2}\end{array}$ & $\begin{array}{c}\text { Zircaloy, SiC } \\
\text { Zircaloy }\end{array}$ & $\begin{array}{l}\mathrm{Ti}_{2} \mathrm{Al}, \text { Nanosteel } \\
\mathrm{Ti}_{2} \mathrm{Al} \text {, Nanosteel }\end{array}$ \\
\hline AREVA & $\begin{array}{c}\mathrm{UO}_{2} \\
\mathrm{UO}_{2}+\mathrm{Cr}_{2} \mathrm{O}_{3} \\
\mathrm{UO}_{2}+\mathrm{Cr}_{2} \mathrm{O}_{3}+\mathrm{SiC} \\
\mathrm{SiC} \\
\end{array}$ & Zircaloy & MAX \\
\hline $\begin{array}{l}\text { General } \\
\text { Electric } \\
\end{array}$ & $\mathrm{UO}_{2}$ & Adv. Steels & $\mathrm{n} / \mathrm{a}$ \\
\hline U. Illinois & $\mathrm{UO}_{2}$ & Mod. $\mathrm{Zr}$ & $\mathrm{n} / \mathrm{a}$ \\
\hline U. Tennessee & $\mathrm{UO}_{2}$ & Zircaloy & Ceramics \\
\hline Georgia Tech & $\mathrm{U}_{3} \mathrm{Si}_{2}$ & $\mathrm{FeCrAl}$ & $\mathrm{n} / \mathrm{a}$ \\
\hline
\end{tabular}

MA-956, Advanced Steel and FeCrAl all refer to advanced Ni-free steels containing about 75\% Fe, 20\% Cr and 5\% Al

This report presents a preliminary systems analysis related to most of these concepts. The potential impacts of these innovative LWR fuels on the front-end of the fuel cycle, on the reactor operation and on the back-end of the fuel cycle are succinctly described without having the pretension of 
being exhaustive. Since the design of these various concepts is still a work in progress, this analysis can only be preliminary and could be updated as the designs converge on their respective final version.

All the proposed enhanced accident tolerant fuel concepts have two important common features:

(1) Their thermal conductivity is higher than that of $\mathrm{UO}_{2}$ and, consequently, they operate at a lower temperature. The energy stored per unit mass of fuel is, consequently, also lower, which is a positive attribute for design basis large break loss of coolant accidents (LBLOCA). Indeed, at the start of the LBLOCA, the fissions quickly cease due to the loss of moderator and insertion of control rods but, with the loss of coolant, the cladding will start to heat up. The stored energy in the pellet redistributes towards a more flat radial temperature profile but heat-up still will occur due the decay heat of the fuel. The initial heat-up of the cladding is mainly due to the redistribution of the stored energy of the pellet, but in the longer term, characteristic of severe accidents, it is the decay heat which is responsible for the heating of the cladding [1.3] and the thermal conductivity of the fuel becomes irrelevant.

(2) Their heat capacity is smaller than that of $\mathrm{UO}_{2}$ which effects the outcome of reactivity induced accidents such as a control rod ejection (or control blade drop in the case of BWRs); for the same reactivity insertion, the maximum power as well as the total energy deposited in the fuel would also be smaller than that deposited in a standard $\mathrm{UO}_{2}$ fuel [1.4]. The reason for such a behavior is that, in case of a reactivity insertion, a fuel with a low heat capacity will see its temperature increase faster than a fuel with a higher heat capacity which means that the temperature feedback will also kick-in faster, hence lowering the height of the power pulse ${ }^{\mathrm{a}}$.

At high temperatures $\left(>1200^{\circ} \mathrm{C}\right)$ that can potentially be reached in severe accidents, zircaloy reacts with steam in an exothermic oxidation reaction, producing hydrogen. This reaction represents a large additional heat source for the cladding and can cause further degradation of the cladding by positive feedback, and the potential for hydrogen burning or absorption. All the proposed enhanced accident tolerant cladding concepts are characterized by total or partial elimination of such exothermic oxidation reactions in order to reduce the temperature excursions in the cladding and thereby gain valuable additional coping time during severe accidents. Note, however, that in case of severe accidents where none or only a very short active cooling period is available, decay heat generation inside the core, even in the absence of the oxidation reaction, is sufficient to result in severe core degradation [1.5]. An example of such a short-term scenario is the short-term station blackout in Fukushima Daiichi Unit1 (0.92 h after

\footnotetext{
${ }^{a}$ The simple adiabatic Nordheim-Fuchs model is reasonably accurate for fast transients such as those induced by a control rod ejection in a PWR. It gives a simple analytical expression to the maximum power as well as energy deposited during a power pulse: $P_{\max } \sim-\frac{C_{p}^{F}(\Delta \rho-\beta)^{2}}{2 \Lambda \alpha_{F}}$ and $E_{d e p} \sim-\frac{2 C_{p}^{F}(\Delta \rho-\beta)}{\alpha_{F}}$, where $C_{p}^{F}, \Delta \rho, \beta, \Lambda$ and $\alpha_{F}$ are, respectively, the fuel heat capacity per unit fuel mass, the reactivity that was initially inserted, the delayed neutron fraction, the prompt neutron life time and the fuel temperature reactivity coefficient. These expressions show that both the maximum power and energy deposited during a power pulse are proportional to the fuel heat capacity.
} 
reactor scram). However, in other scenarios with longer term cooling periods, elimination of heat generation inside the core due to the oxidation reaction can alter the outcome of the accident in its entirety [1.5]. An example of the latter is the long-term station blackout at Fukushima Daiichi Unit 2 that managed intermittent use of reactor core isolation cooling system until $66.8 \mathrm{~h}$ after reactor scram (the decay heat is divided by about a factor of 3 between 1 hour $\left(\sim 1.3 \% \mathrm{P}_{0}\right)$ and 70 hours $\left(\sim 0.4 \% \mathrm{P}_{0}\right)$ after reactor scram).

\section{Fully Ceramic Microencapsulated Fuel}

The tristructural-isotropic (TRISO) fuel developed for high-temperature gas-cooled reactors (HTGRs) is known for its extraordinary fission product retention capabilities. Recently, the possibility of extending the use of TRISO particle fuel to light water reactor technology, and perhaps other reactor concepts, has received significant attention. The fuel form for this purpose, known as fully ceramic microencapsulated (FCM) fuel, embodies a concept that borrows the TRISO fuel particle design from high temperature reactor technology, but uses silicon carbide $(\mathrm{SiC})$ as a matrix material rather than graphite (Fig. 2.1).

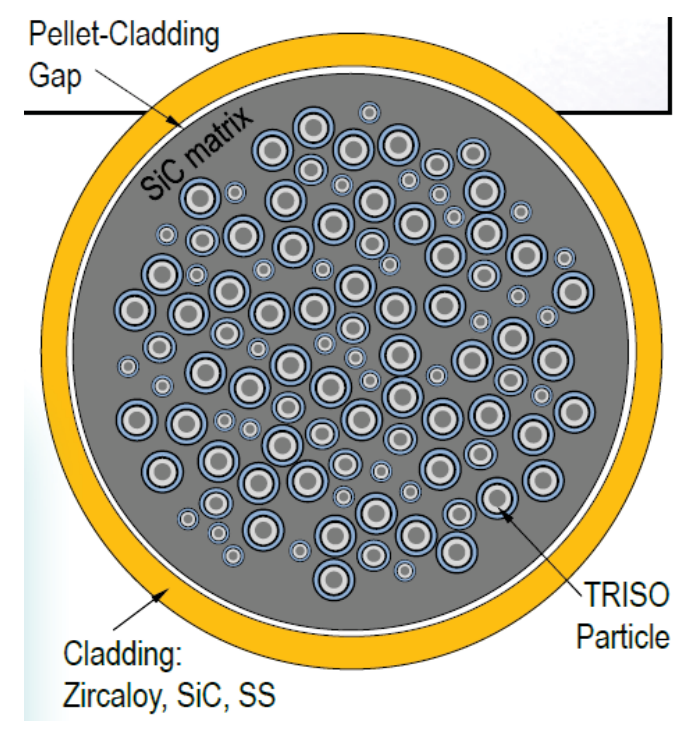

Figure 2.1. Illustration of the FCM fuel concept

The configuration of the FCM pin is a key question for the viability of the FCM concept. The packing fraction of particles within an FCM fuel pin must be higher than the packing fraction of particles in a typical HTGR compact. A recent study suggests that the practical limit for the packing of singlediameter TRISO particles within an HTGR fuel compact is between $40 \%$ and $48 \%$. A conservative estimate of the limit is $44 \%$ for an HTGR compact within a graphite matrix, although packing fractions of 
up to $50 \%$ have been reported experimentally. For the FCM configuration considered here, the matrix is $\mathrm{SiC}$, not graphite. It is unclear what the practical limit is for packing of large-kernel TRISO particles in a $\mathrm{SiC}$ matrix [2.1].

As will be shown in detail below, the FCM concept requires the use of LEU with an initial uranium enrichment of 19.9 w/o, i.e. significantly higher than the $5.0 \mathrm{w} / \mathrm{o}$ licensing limit of current fuel fabrication plants hence the fabrication of FCM assemblies will require adaptation of fuel enrichment facilities and, possibly, transport casks, pool and dry storage facilities at nuclear power plants and repositories.

Overall, the analyses performed so far have shown that the use of standard $\mathrm{UO}_{2}$ TRISO particlesbased (i.e., TRISO particles with 500 micron diameter kernels) FCM fuel compacts in LWRs in a direct replacement of fuel pellets (i.e. keeping the geometry of the fuel assembly unchanged) would result in unacceptably short cycles and in refueling outages perhaps as often as about every 4 months, even with 19.9 w/o enriched uranium [2.2]. This is clearly unacceptable from the point of view of the efficient operation of a LWR and the deployment of such fuel is highly improbable. The reason is that the effective heavy metal density for a fuel compact containing typical TRISO particles (i.e. TRISO particles with 500 micron diameter kernels) with a 44\% TRISO particle packing fraction is only $0.65 \mathrm{~g}_{\mathrm{HM}} / \mathrm{cm}^{3}$, whereas it is about $9 \mathrm{~g}_{\mathrm{HM}} / \mathrm{cm}^{3}$ for a fuel pellet loaded with ordinary $\mathrm{UO}_{2}$ fuel. Consequently, a FCM fuel compact loaded with TRISO particles $(\mathrm{PF}=44 \%$ ) containing $19.9 \mathrm{w} / \mathrm{o}$ enriched uranium contains about 3 times less U-235 than a standard $\mathrm{UO}_{2}$ fuel pellet of the same size.

One way to increase the heavy metal loading of the FCM fuel is to increase the kernel diameter. Analyses showed that it needs to be increased to about 2000 microns in order for a fuel compact to incorporate an amount of fissile material comparable to that contained in a PWR fuel pellet of outer dimensions identical to those of the FCM fuel compact [2.2] [2.3]. However, the feasibility of manufacturing this type of fuel and the effects of the larger kernel diameters on the fuel performance would need further investigation as they are significantly outside the range covered by past experiences. Another way to increase the heavy metal loading of the FCM fuel without compromising the fabrication (i.e. keeping a packing fraction not too far from $44 \%$ and a fuel kernel diameter not too far from the standard 500 microns) is to use a fuel form that possesses a higher heavy metal density than $\mathrm{UO}_{2}$. One such fuel type uses uranium nitride (UN) [2.3] as the dispersed phase $\left(13.5 \mathrm{~g} / \mathrm{cm}^{3}\right.$ heavy metal vs. about $9.2 \mathrm{~g} / \mathrm{cm}^{3}$ for $\mathrm{UO}_{2}$ ). Note, however, that, so far, the bulk of the experience on TRISO fuel particles has been collected with $\mathrm{UO}_{2}, \mathrm{UC}$ and $\mathrm{UCO}$.

In this case, considering a packing fraction equal to $44 \%$ and a $19.9 \mathrm{w} / \mathrm{o}$ enriched uranium 850 micron diameter UN kernel, the FCM fuel assembly contains about the same amount of U-235 as a standard $\mathrm{UO}_{2}$ fuel assembly but the achievable cycle length is approximately 400 EFPD compared to about 500 EFPD for the reference $\mathrm{UO}_{2}$ fuel. Thus, even with an optimistic FCM fuel assembly 
configuration, the cycle length of FCM fuel retrofitted in the reference PWR would have to be reduced by about 100 EFPD [2.4] and, consequently, the cycle length should be reduced from 18 months to about 14 to 15 months. In order to pack enough uranium into the assembly to be able to operate on 18 month cycles it may be necessary to modify the assembly and go from the standard $17 \times 17$ assembly to a $13 \times 13$ assembly design using fuel rods with a larger diameter [2.3]. Such modifications of the geometry of the fuel assembly would probably necessitate development and licensing work to ensure these $13 \times 13$ assemblies meet all the regulatory requirements.

Note, however, that, since the neutron absorption of N14 is large (n-p reaction that produces C14), using N15-enriched nitrogen would increase the cycle lengths to an extent that would need to be evaluated together with the added cost of enriching nitrogen. The amount of nitrogen necessary per GWe$\mathrm{y}$ for the fuel fabrication is between about 300 and $350 \mathrm{~kg}$ (see below) and, since there are currently no nitrogen enrichment capabilities in the US, such an approach would require the development of a new domestic industrial infrastructure. If we consider that the enrichment facilities reject a depleted nitrogen containing $0.1 \% \mathrm{~N} 15$, it takes about $340 \mathrm{~kg}$ of natural nitrogen $(0.366 \% \mathrm{~N} 15)$ to produce $1 \mathrm{~kg}$ of nitrogen containing $90 \%$ of N15. Hence, the amount of natural nitrogen necessary per GWe-y would be between about 100 and 120 tons which seems like a manageable quantity. For instance, the nitrogen production plant located at Thalheim near Leipzig (Germany), the largest in Europe, is designed for 38,000 tons per year in order to satisfy the needs of the photovoltaic industry.

Using N15-enriched nitrogen for the fuel fabrication would have the added benefit of decreasing the amount of $\mathrm{C} 14$ produced by $(\mathrm{n}, \mathrm{p})$ reaction on N14; indeed if the fuel particles are manufactured with natural nitrogen $(99.6 \% \mathrm{~N} 14)$, the amount of $\mathrm{C} 14$ produced would be about 2 orders of magnitude higher than that produced in a standard $\mathrm{UO}_{2}$ fuelled PWR (see Appendix A for detail). The impact on the operation and maintenance of the reactor, the used fuel storage or reprocessing would need to be evaluated because $\mathrm{C} 14$, just like tritium, is mobile in the environment and, consequently, it is important to control its release from nuclear facilities and waste management sites by means of appropriate operational procedures and waste management strategies and practices [2.8].

Regarding the structure of the assemblies, since the liftoff of an assembly could possibly impact control rod insertion, it is important that the fuel assemblies' hold-down mechanism maintain fuel assembly contact with the lower support plate during normal operating anticipated operational occurrences. The fuel assembly lift evaluation is performed by comparing the hold-down force from the hold-down mechanism and fuel assembly weight with that of the hydraulic forces. With this regard, the use of FCM fuel assemblies may require adaptation of the core support structure because the weight of such assemblies would be only about a third of that of standard $\mathrm{UO}_{2}$ fuel assemblies.

Compared to a standard $\mathrm{UO}_{2}$ fuel, the smaller amount of uranium in a FCM core also impacts the reactivity coefficients. In particular, the moderator temperature coefficient tends to be less negative than 
in a standard $\mathrm{UO}_{2}$ core and, consequently, the soluble boron concentration for which the moderator temperature coefficient becomes positive is also lower. Thus, the optimization of a burnable poison strategy will be particularly important to minimize the soluble boron concentration at beginning of cycle.

It is also important to mention that the good behavior of the TRISO particles under PWR operating conditions still needs to be confirmed since under these conditions the fast neutron fluence (above $100 \mathrm{keV}$ ) experienced by the TRISO particles should be about a factor of 4 to 5 higher than that experienced in an HTGR for which this fuel was originally developed. Indeed, since both the cycle length and the power density of a PWR are higher than that of a HTGR, the peak fast neutron fluence should be of the order of $20 \times 10^{21} \mathrm{n} . \mathrm{cm}^{-2}$ [2.2] [2.3] whereas it is about $4.5 \times 10^{21} \mathrm{n} . \mathrm{cm}^{-2}$ in a HTGR. For the same fuel management as a standard $\mathrm{UO}_{2}$ fuel, i.e. $3 \times 18$ months, the peak pin burnup would also be about 220 $\mathrm{GWd} / \mathrm{t}$ which is higher than the values available in the experimental databases. If, in these conditions, a substantial number of TRISO particles are shown to fail, the FCM concept would need to be significantly revised. For example, going from a $3 \times 18$ months to a $3 \times 12$ months fuel management and lowering the power of the reactor would decrease the fast neutron fluence experienced by the TRISO particles. The economic penalty associated with such a solution would probably not be acceptable to the operators.

A standard $\mathrm{UO}_{2}$ fuelled PWR needs about 22 tons of 4.2 w/o enriched uranium per GWe-y. If we consider, as a first approximation, that the FCM fuel requires the same amount of U-235 than a standard $\mathrm{UO}_{2}$ fuel to produce the same energy, the amount of LEU (19.9 w/o enriched) can be estimated to be about 4.7 tons per GWe-y which necessitates about 200 tons of natural uranium and 194,000 Separating Work Unit (SWU) per GWe-y, i.e. about, respectively, 5\% and 40\% more than what is necessary for a standard $\mathrm{UO}_{2}$ fuelled PWR (190 tons and 138 kSWU per GWe-y). Even though preliminary, the analyses available tend to show that the FCM fuel will actually need more U-235 than a standard $\mathrm{UO}_{2}$ fuel to meet the same cycle length, hence a range of 5 to 6 tons of LEU ( 19.9 w/o enriched) per GWe-y may be more realistic together with a mass flow of nitrogen of between about 300 and $350 \mathrm{~kg}$ per GWe-y. In that case, the amount of natural uranium necessary would be between about 215 and 255 tons per GWe-y, i.e. between about $15 \%$ and $35 \%$ higher than for the standard $\mathrm{UO}_{2}$ fuel. The enrichment process would require between 205 and $245 \mathrm{kSWU}$ per GWe-y, i.e. between about 50\% and 80\% higher than for the standard $\mathrm{UO}_{2}$ fuel (about $138 \mathrm{kSWU}$ per GWe-y). The amount of depleted uranium that would need to be stored would be between about 210 tons and 250 tons per GWe-y, i.e. between $25 \%$ and $50 \%$ higher than the amount of depleted uranium generated during the production of the 22 tons of $4.2 \mathrm{w} / \mathrm{o}$ enriched uranium (about 170 tons per GWe-y).

Concerning the fabrication cost of FCM fuel, it is possible to get an order of magnitude if we consider that a FCM fuel assembly contains about $150 \mathrm{~kg}$ of LEU (compared to $539 \mathrm{~kg}$ for a standard UO2 assembly). If these $150 \mathrm{~kg}$ are contained in 800 microns TRISO particles, it comes that there are approximately 5 million TRISO particles per assembly. From Table 2.1, the fuel and clad fabrication 
costs for a standard UO2 assembly are about $\$ 135 \mathrm{k}$, out of which about $\$ 30 \mathrm{k}$ is for the clad. Hence, the fabrication cost of a standard $\mathrm{UO}_{2}$ fuel is approximately $\$ 100 \mathrm{k}$ per assembly. Consequently, if 5 million TRISO particles containing $150 \mathrm{~kg}$ LEU could be fabricated, packed into the $\mathrm{SiC}$ matrix and assembled into rods for about $\$ 100 \mathrm{k}$, then both fuel fabrications would cost the same. Hence, the FCM break-even fabrication cost seems to be around 2 cents per TRISO or, put differently, \$667 per kg of LEU.

Table 2.1 Cost of a $\mathrm{UO}_{2}$ assembly in an AP-1000 core [2.6]

\begin{tabular}{|c|c|c|}
\hline & $\begin{array}{l}\text { Unit Cost } \\
{[100]}\end{array}$ & $\begin{array}{c}\text { AP-1000 } \\
17 \times 17 \\
\text { Assembly } \\
\text { Cost }[\mathrm{k} \$]\end{array}$ \\
\hline $\begin{array}{l}\text { Uranium } \\
\text { Mining/Milling }\end{array}$ & $75[\$ / \mathrm{kgNatU}]$ & 462 \\
\hline Conversion & $10[\$ / \mathrm{kgNatU}]$ & 62 \\
\hline Enrichment & 110 [\$/SWU] & 427 \\
\hline DU Disposal & $11[\$ / \mathrm{kgDU}]$ & 62 \\
\hline Fuel/Clad Fabrication & $250[\$ / \mathrm{kgLEU}]$ & 135 \\
\hline Total & & 1147 \\
\hline
\end{tabular}

Note that the TRISO fuel fabrication cost estimate presented in reference [2.7] is significantly higher than the estimated $\$ 667$ per $\mathrm{kg}$ of LEU break-even cost. Indeed, the fabrication cost of the TRISO fuel is estimated to be between about $\$ 10 \mathrm{k}$ and $\$ 26 \mathrm{k}$ per $\mathrm{kg}$ of LEU (respectively, $\mathrm{n}^{\text {th }}$-of-a-kind and firstof-a-kind), i.e. between about 15 and 39 times higher than the estimated FCM break-even cost. Hence, unless the TRISO fabrication cost is drastically reduced and/or the use of FCM fuel allows longer cycle length and/or power uprates, this concept may be difficult to justify from an economic standpoint.

Regarding the back-end of the fuel cycle, the main difference between the FCM fuel and the standard $\mathrm{UO}_{2}$ fuel resides in the mass of heavy metal that needs to be stored. For a standard $\mathrm{UO}_{2}$ fuelled PWR, irradiated to a burnup of $50 \mathrm{GWd} / \mathrm{t}$, about 22 tons of heavy metal need to be stored per GWe-y. These 22 tons essentially contain uranium together with about 1 ton of fission products and $290 \mathrm{~kg}$ of transuranics (plutonium and minor actinides). In the case of the FCM fuelled PWR, only between 5 and 6 tons of heavy metal would need to be stored per GWe-y. These 5 to 6 tons would also contain essentially uranium together with about 1 ton of fission products and about $90 \mathrm{~kg}$ of transuranics. The plutonium present in the used FCM fuel will also contain a much higher proportion of $\mathrm{Pu}-238$ than in the $\mathrm{UO}_{2}$ fuel, hence rendering it more proliferation resistant. The uranium present in the used FCM fuel should also contain a higher proportion of U-235 (a few w/o) [2.1] than that in a standard used $\mathrm{UO}_{2}$ fuel $(\sim 1 \mathrm{w} / \mathrm{o})$.

Note that, even though the masses of heavy metal present in the used FCM and $\mathrm{UO}_{2}$ fuel differ significantly, the volumes are the same since the assemblies have the same geometry. The decay heat up 
to a few decades should also be very similar since it is driven by the amount of fission products which, for the same energy produced, are the same in both cases. Hence, the requirements in terms of transportation and storage casks should be similar. On the other hand, since the FCM fuel contains about 3 times less transuranics than a standard $\mathrm{UO}_{2}$ fuel, the long term ( $>100$ years) decay heat will be substantially lower, which is a positive feature.

If the fuel is to be reprocessed, the coating layers around the fuel kernel must be removed in order to provide reagent access to the fuel material. Both aqueous and non-aqueous processes are being developed, initially in concept only, for the reprocessing of these fuels [2.5]. The development of the processing technology for TRISO fuels can build to some extent on experience gained during the 1970s, when a process involving burning of the outer layers of graphite was developed. The fuel particles were crushed by passing through a set of steel rollers, exposing the fuel material for dissolution by nitric acid. The balance of the process followed a standard PUREX flowsheet. Considerable problems were posed by off- gas handling, and recovery efficiencies were not particularly high.

Non-aqueous processes now being studied for application to the reprocessing of TRISO fuel include fluoride and chloride volatility processes, carbo-chlorination processes, and direct electrochemical dissolution. A problem common to all of these conceptual processes is the disposition of the large amount of carbon and silicon remaining from the processing of this fuel. Waste volumes can be very large, even though the fuel burn-up capability might be quite high [2.5].

\section{U-Mo Fuel}

The uranium-molybdenum fuel (U-Mo) is a metallic fuel. Its thermal conductivity is about ten times that of $\mathrm{UO}_{2}$ (respectively 37 and $4 \mathrm{~W} / \mathrm{m}-\mathrm{K}$ ) and its heat capacity is about half that of UO2 fuel (respectively about 145 and $300 \mathrm{~J} / \mathrm{kg}-\mathrm{K}$ at $500{ }^{\circ} \mathrm{C}$ ). The heavy metal density of U-Mo fuel is about $70 \%$ higher than that in $\mathrm{UO}_{2}$ which, in principle, should allow lower fuel enrichments and/or longer cycle lengths. On the other hand, its melting point is significantly lower than that of $\mathrm{UO}_{2}$ (respectively $1150{ }^{\circ} \mathrm{C}$ and $2840{ }^{\circ} \mathrm{C}$ ) and the parasitic neutron absorption in the fuel, due to the presence of molybdenum, is much higher than that in $\mathrm{UO}_{2}$ fuel.

The basic LWR U-Mo fuel concept is shown in Figure 3.1 [3.1]. It consists of an annular U-Mo fuel region with an open center annulus which functions as a fission gas plenum and to accommodate irradiation swelling. A layer enriched in aluminum, chromium, and/or niobium is diffused into the outer U-Mo region and functions to reduce or impede any metal-water reaction should a cladding breach occur. This layer is particularly important because, unlike $\mathrm{UO}_{2}, \mathrm{U}-\mathrm{Mo}$ dissolves when in contact with hot water (corrosion rates of U-Mo metal fuel alloys are high enough that unclad fuel life is on the order of a few weeks in water at $300^{\circ} \mathrm{C}$ ). 
There are a wide variety of options for the outer barrier cladding, such as advanced zirconium or steel alloys, $\mathrm{SiC}$, and $\mathrm{FeCrAl}$ candidates (see the following sections for more details on these concepts). Multiple alternative cladding concepts are being explored. The selection of cladding material decision is dependent upon which material will provide the most advantageous behavior in the event of a loss-ofcoolant accident.

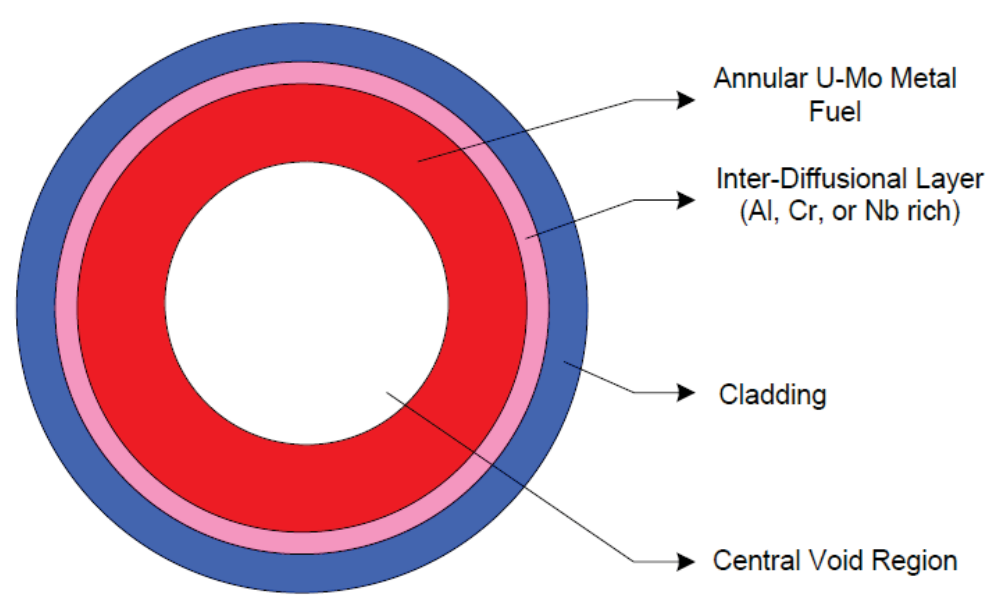

Figure 3.1 Illustration of the annular U-Mo fuel concept [3.1]

The existing fabrication processes developed for $\mathrm{UO}_{2}$ fuels are very different from those necessary for the fabrication of U-Mo fuel. Indeed, in order to develop a commercially feasible U-Mo fuel design and production process it is necessary to demonstrate the ability to extrude a cast U-Mo ingot material into a smaller diameter rod product [3.1]. Although some extrusion of depleted uranium and metal fuels has been done on a large scale in the past, very limited capability currently exists within industry or the DOE laboratory complex for the extrusion of small diameter metal fuels. If we consider that the U-Mo fuel assemblies generate the same energy and operate with the same average linear power as standard $\mathrm{UO}_{2}$ assemblies $(\sim 18 \mathrm{~kW} / \mathrm{m})$, the amount of $\mathrm{U}-\mathrm{Mo}$ fuel that needs to be fabricated is about 45 km per GWe-y.

Due to the high neutron absorption of molybdenum (especially Mo-95), the amount of U-235 in a $\mathrm{U}-\mathrm{Mo}$ fuel assembly will be higher than that in a standard $\mathrm{UO}_{2}$ fuel assembly. If we consider that the ratio of uranium density in a $U-M o$ fuel to that in a standard $\mathrm{UO}_{2}$ fuel is 1.7 , i.e. $\frac{d_{U}^{U-M o}}{d_{U}^{U O 2}}=1.7$, the mass of uranium in the U-Mo assembly relative to that in the standard $\mathrm{UO}_{2}$ assembly will depend on the dimension of the central hole. The design of the fuel is not finalized yet but, for example, the mass of uranium in a $8.2 \mathrm{~mm}$ diameter U-Mo fuel with a central hole diameter of $5.3 \mathrm{~mm}$ will be about the same as that in a standard $8.2 \mathrm{~mm}$ diameter $\mathrm{UO}_{2}$ fuel. For central hole diameters of $4 \mathrm{~mm}$ and $3 \mathrm{~mm}$ the mass of uranium in the U-Mo fuel pellet will be, respectively, about $30 \%$ and $47 \%$ higher than that in a standard $\mathrm{UO}_{2}$ assembly. 
Preliminary calculations performed considering a 17×17 PWR fuel assembly loaded with U10Mo fuel (10 w/o molybdenum) and clad with standard zircaloy show that, in the $5.3 \mathrm{~mm}$ diameter central hole case, the U-235 enrichment is about 4.7 w/o for a $3 \times 18$ month fuel management, compared to $4.2 \mathrm{w} / \mathrm{o}$ for the reference $\mathrm{UO}_{2}$ fuel [3.2]. Since the burnups are similar for both cases, they both need about 22 tons of LEU per GWe-y (4.7 w/o for U-10Mo and $4.2 \mathrm{w} / \mathrm{o}$ for $\mathrm{UO}_{2}$ ). Consequently, the U-10Mo fuel concept needs about 13\% more natural uranium than the reference $\mathrm{UO}_{2}$ fuel (respectively about 215 and 190 tons per GWe-y) and about 17\% more SWU (respectively about 160 and 138 kSWU per GWe-y). The amount of depleted uranium increases also by about 15\%, i.e. from about 170 tons to 195 tons per GWe-y. In addition to the 22 tons of LEU, the U-10Mo fuel needs about 2.5 tons of molybdenum per GWe-y. Note that, with an annual molybdenum production of between 50,000 and 60,000 tons, the US is the second producer in the world behind China.

In the case of a $4 \mathrm{~mm}$ central hole case, the U-10Mo fuel assemblies will contain about $30 \%$ more uranium than the standard $\mathrm{UO}_{2}$ fuel assemblies and the U-235 enrichment should be only about $4.2 \mathrm{w} / \mathrm{o}$ for the same $3 \times 18$ month fuel management [3.2]. However, since this U-10Mo assembly contains about $30 \%$ more uranium than the standard $\mathrm{UO}_{2}$ assembly, the burnup will also be lower by about a factor 1.3. Hence, the amount of $4.2 \mathrm{w} / \mathrm{o}$ enriched uranium necessary is about $22 \times 1.3=28.6$ tons per GWe-y which requires about 245 tons of natural uranium and $180 \mathrm{kSWU}$ per GWe-y $(30 \%$ more than for the reference $\mathrm{UO}_{2}$ fuel). In this specific case, the mass of uranium in the fuel assemblies is such that it would allow for $3 \times 23$ month fuel management with a 5.1 w/o enriched uranium (burnup of $\sim 50 \mathrm{GWd} / \mathrm{t}$ ). This fuel management would require the fabrication of about 22 tons of LEU per GWe-y using about 230 tons of natural uranium and $180 \mathrm{kSWU}$ per GWe-y (respectively, about $20 \%$ and $30 \%$ more than for the reference $\mathrm{UO}_{2}$ fuel). In addition, 2.5 tons of molybdenum per GWe-y would also be necessary.

Since the isotope Mo-95 ( $15.9 \%$ in molybdenum) is responsible for most of the neutron absorption in molybdenum, using molybdenum depleted in this particular isotope would eliminate, or at least mitigate, the impact on the uranium enrichment. The added cost coming from depleting the 2.5 tons per GWe-y of molybdenum versus the benefit coming from lowering the uranium enrichment of the 22 tons per GWe-y of LEU would need to be analyzed. Note that URENCO has already studied the possibility to enrich/deplete molybdenum in the past (see Appendix $\mathrm{C}$ for detail).

From the numbers presented above, it is possible to estimate the break-even cost of depleting molybdenum. For example, if we consider the $3 \times 18$ month fuel management using fuel pellets with a 5.3 $\mathrm{mm}$ central hole diameter $(50 \mathrm{GWd} / \mathrm{t})$, it comes that depleting 2.5 tons of molybdenum per GWe-y so that it contains almost no Mo-95 could potentially bring about an economy of about 25 tons of natural uranium per GWe-y (190 tons instead of 215 tons) and of $22 \mathrm{kSWU}$ per GWe-y (138 kSWU instead of $160 \mathrm{kSWU}$ ). If we consider $\$ 85 / \mathrm{kg}-\mathrm{NU}$ for uranium mining, milling and conversion as well as $\$ 110 / \mathrm{SWU}$ for enrichment (see Table 2.1), it comes that the potential economy is about $\$ 4.5 \mathrm{M}$ per GWe-y. Hence, 
the break-even cost of depleting molybdenum seems to be around $\$ 1.8 \mathrm{k}$ per $\mathrm{kg}$ of molybdenum $(\$ 4.5 \mathrm{M}$ divided by $2500 \mathrm{~kg}$ of molybdenum); below this value, the cost of depleting molybdenum is more than compensated by the economies on natural enrichment mining, milling, conversion and enrichment, whereas above this value it is not the case.

Regarding reactor operation, the reactivity coefficients will be impacted to an extent that will depend on the mass of uranium present in the assembly. Depending of the size of the pellet central hole, the mass of uranium in a U-Mo assembly could be as high as $50 \%$ higher than that in a standard $\mathrm{UO}_{2}$ assembly. Such a decrease in the hydrogen-to-uranium atom ratio will impact the neutron spectrum in the assembly and, consequently, the moderator temperature reactivity coefficient, the soluble boron reactivity coefficient, the control rod worth and, to a lesser extent, the fuel temperature reactivity coefficient. The impact on reactor operation, reactivity shutdown margins and on the outcome of transients will need to be re-evaluated. The higher mass of heavy metal in the assemblies may also have an impact on the lower core support plate which may have to be reinforced in order to ensure proper support of the additional weight. Indeed, in the case of a core containing 157 assemblies, such as the AP1000, the additional weight could potentially add up to about 40 tons for a central pellet hole diameter of about $3 \mathrm{~mm}$.

Note that, even though the masses of heavy metal present in the used $\mathrm{U}-\mathrm{Mo}$ and $\mathrm{UO}_{2}$ fuel may differ, the volumes are the same since the assemblies have the same geometry. The decay heat up to a few decades should also be very similar since it is driven by the amount of fission products which, for the same energy produced, are the same in both cases. Hence, the requirements in terms of transportation and storage casks should be similar.

Aqueous technologies are currently the reference route for industrial scale used fuel reprocessing. The processes derived from PUREX are able to deal with a large variety of used fuels (oxides, carbides, nitrides). They can also be adapted to co-laminated fuels such as U-Mo, U-Si, U-Al or Pu-Al [2.5]. Hence, if the U-Mo fuel is to be reprocessed, it could probably be done without major modifications to existing industrial aqueous processes.

\section{UN Fuel}

Uranium mononitride (UN) has been studied fairly extensively as a reactor fuel but has not been used in any reactor. It possesses a combination of desirable properties: a high melting temperature (2762 ${ }^{\circ} \mathrm{C}$ ), good thermal conductivity (about $20 \mathrm{~W} / \mathrm{m}-\mathrm{K}$ vs. about $4 \mathrm{~W} / \mathrm{m}-\mathrm{K}$ for $\mathrm{UO}_{2}$ ), high uranium density $\left(13.5 \mathrm{~g} / \mathrm{cm}^{3}\right.$ vs. $9.6 \mathrm{~g} / \mathrm{cm}^{3}$ for $\left.\mathrm{UO}_{2}\right)$, compatibility with most potential cladding materials, and good irradiation stability and fission product retention. The heat capacity of $\mathrm{UN}$ is also about $25 \%$ lower than that of $\mathrm{UO}_{2}$ fuel (respectively about 230 and $300 \mathrm{~J} / \mathrm{kg}-\mathrm{K}$ at $500{ }^{\circ} \mathrm{C}$ ). As mentioned in the FCM section, a disadvantage of nitride fuel is related to the large parasitic neutron capture $(n, p)$ reaction of the main 
nitrogen isotope (N14) which, consequently, require higher U-235 loading compared to that in a standard $\mathrm{UO}_{2}$ fuel in order to compensate for this additional absorption. Enriching nitrogen in N15 would eliminate, or at least mitigate, the impact on the uranium enrichment (see below).

The amount of nitrogen necessary per GWe-y for the fuel fabrication is between about 1.3 and 1.8 tons (see below) and, since there are currently no nitrogen enrichment capabilities in the US, such an approach would require the development of a new domestic industrial infrastructure. If we consider that the enrichment facilities reject a depleted nitrogen containing $0.1 \% \mathrm{~N} 15$, it takes about $340 \mathrm{~kg}$ of natural nitrogen $(0.366 \% \mathrm{~N} 15)$ to produce $1 \mathrm{~kg}$ of nitrogen containing $90 \%$ of N15. Hence, the amount of natural nitrogen necessary per GWe-y would be between about 440 and 610 tons which seems like manageable quantities. For instance, the nitrogen production plant located at Thalheim near Leipzig (Germany), the largest in Europe, is designed for 38,000 tons per year in order to satisfy the needs of the photovoltaic industry.

However, a major drawback of UN fuel, which needs to be addressed successfully prior to any deployment in existing LWR, is its extremely low oxidation resistance (UN powders oxidize in air and UN pellets decompose in hot water). Research is currently underway to solve this problem and thereby provide an accident tolerant fuel that would resist water leaks and high temperature steam oxidationspalling during an accident [4.1]. Two possible methods are under investigation to increase the oxidation resistance of $\mathrm{UN}$ : (1) Addition of $\mathrm{USi}_{\mathrm{x}}$ (e.g. $\mathrm{U}_{3} \mathrm{Si}_{2}$ ) to $\mathrm{UN}$ nitride powder, followed by liquid phase sintering, and (2) "alloying" UN nitride with compounds that will greatly increase oxidation resistance.

The irradiation swelling of UN fuel is less than that of U-Mo fuel and, consequently, it is not necessary to fabricate annular pellets. Standard size fuel pellets are, indeed, considered for implementation of UN fuel in PWRs which means that a UN fuel assembly would contain about $40 \%$ more uranium than a standard $\mathrm{UO}_{2}$ assembly if a clad having the same wall thickness as the standard $\mathrm{Zr}$ clad is used. Hence, for the reference $3 \times 18$ month fuel management, corresponding to a burnup of 50 $\mathrm{GWd} / \mathrm{t}$ for the standard $\mathrm{UO}_{2}$ assembly, the burnup of the $\mathrm{UN}$ assembly would only be about $36 \mathrm{GWd} / \mathrm{t}$ (power uprates, though a possibility, are not considered here). An increase of the cycle length from 18 months to about 25 months would allow reaching the same $50 \mathrm{GWd} / \mathrm{t}$ in the $\mathrm{UN}$ fuel.

Preliminary calculations performed considering a 17×17 PWR fuel assembly loaded with UN fuel and clad with standard zircaloy [4.2] show that the U-235 enrichment would be about 4.5 w/o for a $3 \times 18$ month fuel management, compared to 4.2 w/o for the reference $\mathrm{UO}_{2}$ fuel, if natural nitrogen was used. If enriched nitrogen containing 50 or 90 w/o of N15 was used instead, the U-235 enrichment would be, respectively, about 3.9 and $3.4 \mathrm{w} / \mathrm{o}$. Since the UN fuel burnup corresponding to a $3 \times 18$ month fuel management is about $36 \mathrm{GWd} / \mathrm{t}$, the amount of LEU and nitrogen necessary are equal to, respectively, about 31 and 1.8 tons per GWe-y. The corresponding masses of natural uranium are 285, 245 and 210 
tons per GWe-y for UN fuels using, respectively, natural nitrogen, 50 w/o N15 nitrogen and 90 w/o N15 nitrogen.

For a $3 \times 25$ month fuel management, corresponding to a UN fuel burnup of $50 \mathrm{GWd} / \mathrm{t}$, the U-235 enrichments would be about 5.7, 5.1 and 4.6 w/o [4.2] for, respectively, natural nitrogen, 50 w/o N15 nitrogen and $90 \mathrm{w} / \mathrm{o}$ N15 nitrogen. The amount of LEU and nitrogen necessary are equal to, respectively, about 22 and 1.3 tons per GWe-y. The corresponding masses of natural uranium and SWU are, respectively, 260, 230 and 205 tons per GWe-y and 208, 180 and 156 kSWU per GWe-y for UN fuels using natural nitrogen, $50 \mathrm{w} / \mathrm{o}$ N15 nitrogen or $90 \mathrm{w} / \mathrm{o}$ N15 nitrogen. This represents between about $8 \%$ and $37 \%$ more natural uranium and between about $13 \%$ and $50 \%$ more SWU than for the standard $\mathrm{UO}_{2}$ fuel (190 tons and $138 \mathrm{kSWU}$ per GWe-y).

From these numbers, it comes that enriching 1.3 tons of nitrogen per GWe-y so that it contains $90 \%$ of N15 brings about an economy of about 55 tons of natural uranium per GWe-y (205 tons instead of 260 tons) and of $52 \mathrm{kSWU}$ per GWe-y (156 kSWU instead of $208 \mathrm{kSWU})$. If we consider $\$ 85 / \mathrm{kg}-\mathrm{NU}$ for uranium mining, milling and conversion as well as $\$ 110 /$ SWU for enrichment (see Table 2.1), it comes that the economy is about $\$ 10.4 \mathrm{M}$ per GWe-y. Hence, the break-even cost of enriching nitrogen seems to be around $\$ 8.9 \mathrm{k}$ per $\mathrm{kg}$ of N15 $(\$ 10.4 \mathrm{M}$ divided by $0.9 \times 1300 \mathrm{~kg}$ of N15) ; below this value, the cost of enriching nitrogen is more than compensated by the economies on natural enrichment mining, milling, conversion and enrichment, whereas above this value it is not the case.

Regarding reactor operation, the reactivity coefficients will be impacted because the mass of uranium in a $\mathrm{UN}$ assembly is about $40 \%$ higher than that in a standard $\mathrm{UO}_{2}$ assembly. Such a change in the hydrogen-to-uranium atom ratio will impact the neutron spectrum in the assembly and, consequently, the moderator temperature reactivity coefficient, the soluble boron reactivity coefficient, the control rod worth and, to a lesser extent, the fuel temperature reactivity coefficient. The impact on reactor operation, reactivity shutdown margins and on the outcome of transients will need to be re-evaluated. The higher mass of heavy metal in the assemblies may also have an impact on the lower core support plate which may have to be reinforced in order to ensure proper support of the additional weight. Indeed, in the case of a core containing 157 assemblies, such as the AP1000, the additional weight could potentially add up to about 30 tons.

As mentioned in the FCM section, the amount of $\mathrm{C} 14$ produced in a fuel containing nitrogen will be higher than that produced in a $\mathrm{UO}_{2}$ fuel because of the $(n, p)$ reaction on N14. Considering a $90 \%$ N15enriched nitrogen, the amount of $\mathrm{C} 14$ produced in the UN fuel would be about 2 orders of magnitude higher than that produced in a standard $\mathrm{UO}_{2}$ fuelled PWR. Enriched nitrogen made up of $99.9 \% \mathrm{~N} 15$ and $0.1 \% \mathrm{~N} 14$ would be necessary to maintain the same level of C14 produced as that in a standard $\mathrm{UO}_{2}$ fuel. (see Appendix B for detail). The impact on the operation and maintenance of the reactor, the used fuel storage or reprocessing would need to be evaluated because $\mathrm{C} 14$, just like tritium, is mobile in the 
environment and, consequently, it is important to control its release from nuclear facilities and waste management sites by means of appropriate operational procedures and waste management strategies and practices [2.8].

Regarding the back-end of the fuel cycle, preliminary calculations [4.2] show that the used UN fuel contains about $25 \%$ more transuranics than the standard $\mathrm{UO}_{2}$ fuel. Indeed, for a $3 \times 25$ month fuel management, corresponding to a UN fuel burnup of $50 \mathrm{GWd} / \mathrm{t}$, the 22 tons of used UN fuel generated per GWe-y contain about $360 \mathrm{~kg}$ of transuranics compared to about $290 \mathrm{~kg}$ for the standard $\mathrm{UO}_{2}$ fuel. The impact on transportation and storage will need to be evaluated. Furthermore, as mentioned earlier, the processes derived from PUREX are able to deal with a large variety of used fuels (oxides, carbides, nitrides) whatever are the nature and shape of the fissile composite. Hence, if the UN fuel is to be reprocessed, it could probably be done without major modifications to existing industrial aqueous processes.

\section{5. $\mathrm{U}_{3} \mathrm{Si}_{2}$ Fuel}

Just like U-Mo and UN fuels, $\mathrm{U}_{3} \mathrm{Si}_{2}$ fuel has a higher heavy metal density $\left(11.3 \mathrm{~g} / \mathrm{cm}^{3}\right)$ and thermal conductivity (about $15 \mathrm{~W} / \mathrm{m}-\mathrm{K}$ ) compared to $\mathrm{UO}_{2}$ fuel (respectively $9.6 \mathrm{~g} / \mathrm{cm}^{3}$ and $4 \mathrm{~W} / \mathrm{m}-\mathrm{K}$ ). Its heat capacity is about $17 \%$ lower than that of $\mathrm{UO}_{2}$ fuel (respectively about 250 and $300 \mathrm{~J} / \mathrm{kg}-\mathrm{K}$ at $500{ }^{\circ} \mathrm{C}$ ). Its melting temperature is equal to $1665^{\circ} \mathrm{C}$, i.e. in between those of U-Mo and UN fuels. It also has two important advantage compared to the U-Mo and UN fuels: (1) it does not decompose when in contact with hot water and (2) the parasitic neutron absorption due to Si is very small.

The irradiation swelling of $\mathrm{U}_{3} \mathrm{Si}_{2}$ fuel may make it necessary to implement some modifications to the pellet design such as the use of annular pellet or the use of a smaller pellet diameter. Since the heavy metal density of $\mathrm{U}_{3} \mathrm{Si}_{2}$ is only about $18 \%$ higher than that of $\mathrm{UO}_{2}$, if such measures have to be implemented the heavy metal loading of $\mathrm{U}_{3} \mathrm{Si}_{2}$ fuel assemblies could actually be lower than that of standard $\mathrm{UO}_{2}$ assemblies. The break-even $\mathrm{U}_{3} \mathrm{Si}_{2}$ fuel pellet diameter is $7.56 \mathrm{~mm}$, i.e. a $7.56 \mathrm{~mm}$ diameter $\mathrm{U}_{3} \mathrm{Si}_{2}$ fuel pellet contains the same quantity of uranium as a standard $8.2 \mathrm{~mm}$ diameter $\mathrm{UO}_{2}$ fuel pellet. Hence, for the reference $3 \times 18$ month fuel management, corresponding to a burnup of $50 \mathrm{GWd} / \mathrm{t}$ for the standard $\mathrm{UO}_{2}$ assembly, the burnup of the $\mathrm{U}_{3} \mathrm{Si}_{2}$ assembly would only be about $42.5 \mathrm{GWd} / \mathrm{t}$ (power uprates, though a possibility, are not considered here) if it uses standard size fuel pellets $(8.2 \mathrm{~mm}$ diameter). An increase of the cycle length from 18 months to about 21 months would allow reaching the same $50 \mathrm{GWd} / \mathrm{t}$ in the $\mathrm{U}_{3} \mathrm{Si}_{2}$ fuel. If the $\mathrm{U}_{3} \mathrm{Si}_{2}$ pellet diameter is reduced to its break-even diameter (7.56 $\mathrm{mm}$ ), the reference $3 \times 18$ month fuel management will also correspond to a burnup of $50 \mathrm{GWd} / \mathrm{t}$.

Preliminary calculations performed considering a $17 \times 17$ PWR fuel assembly loaded with $8.2 \mathrm{~mm}$ $\mathrm{U}_{3} \mathrm{Si}_{2}$ fuel pellets and clad with standard zircaloy [5.1] show that the U-235 enrichment would be about 
$3.7 \mathrm{w} / \mathrm{o}$ for a $3 \times 18$ month fuel management, compared to $4.2 \mathrm{w} / \mathrm{o}$ for the reference $\mathrm{UO}_{2}$ fuel. Since the $\mathrm{U}_{3} \mathrm{Si}_{2}$ fuel burnup corresponding to a $3 \times 18$ month fuel management is about $42.5 \mathrm{GWd} / \mathrm{t}$, the amount of LEU and necessary is equal to about 26 tons per GWe-y. The corresponding masses of natural uranium and SWU are, respectively, 195 tons per GWe-y and 135 kSWU per GWe-y, i.e. very close to the values obtained with standard $\mathrm{UO}_{2}$ fuel (190 tons and $138 \mathrm{kSWU}$ per GWe-y). For a 3×21 month fuel management, corresponding to an $\mathrm{U}_{3} \mathrm{Si}_{2}$ fuel burnup of $50 \mathrm{GWd} / \mathrm{t}$, the $\mathrm{U}-235$ enrichment would be about 4.2 w/o, i.e. the same as for the standard $\mathrm{UO}_{2}$ fuel. Consequently, the masses of natural uranium and SWU will also be the same, i.e. 190 tons and $138 \mathrm{kSWU}$ per GWe-y.

If we consider, as a first approximation, that the U-235 loading necessary to produce a given amount of energy is independent of the pellet diameter, it comes that the U-235 enrichment of the 7.56 mm diameter $\mathrm{U}_{3} \mathrm{Si}_{2}$ fuel pellets would be about 4.35 w/o for the $3 \times 18$ month fuel management (i.e. $3.7 \times$ $\left.(8.2 \div 7.56)^{2}\right)$. Since in this case the $\mathrm{U}_{3} \mathrm{Si}_{2}$ fuel assemblies would contain the same mass of uranium as the standard $\mathrm{UO}_{2}$ fuel assemblies, the burnup corresponding to the reference $3 \times 18$ month fuel management would also be the same, i.e. $50 \mathrm{GWd} / \mathrm{t}$ and the amount of LEU and necessary is equal to about 22 tons per GWe-y. The corresponding masses of natural uranium and SWU are, respectively, 196 tons per GWe-y and 145 kSWU per GWe-y, i.e. about 3-5\% more than that with standard $\mathrm{UO}_{2}$ fuel.

Regarding the back-end of the fuel cycle, preliminary calculations [5.1] show that the used $\mathrm{U}_{3} \mathrm{Si}_{2}$ fuel may contain more TRU than the standard $\mathrm{UO}_{2}$ fuel depending of the configuration. Indeed, for a $3 \times 21$ month fuel management, corresponding to a $\mathrm{U}_{3} \mathrm{Si}_{2}$ fuel burnup of $50 \mathrm{GWd} / \mathrm{t}$, the 22 tons of used $\mathrm{UN}$ fuel generated per GWe-y contain about $315 \mathrm{~kg}$ of TRU compared to about $290 \mathrm{~kg}$ for the standard $\mathrm{UO}_{2}$ fuel. The impact on transportation and storage will need to be evaluated. Furthermore, as mentioned earlier, the processes derived from PUREX are able to deal with a large variety of used fuels and can be adapted to process $\mathrm{U}-\mathrm{Si}$ fuels. Hence, if the $\mathrm{U}_{3} \mathrm{Si}_{2}$ fuel is to be reprocessed, it could probably be done without major modifications to existing industrial aqueous processes.

\section{Silicon Carbide Cladding}

The use of silicon carbide ( $\mathrm{SiC}$ ) materials in cladding designs is promising for improved performance in certain areas under LWR core conditions, particularly under conditions where properties of zirconium based alloys could be significantly degraded, such as loss of coolant accidents. In particular, unlike zirconium based alloys, $\mathrm{SiC}$ is not subject to an exothermic reaction with steam, and associated (significant) hydrogen production. SiC-based cladding for nuclear fuel may provide larger safety margins during transients and high burnup capability with longer cycle lengths or uprated operation (i.e. higher heat fluxes). 
The key features of the $\mathrm{SiC}$ cladding that favor its further development and application to commercial water reactors include the following [6.1]:

a. Accident tolerance - ballooning - Because the SiC clad maintains its strength even at high temperature, it would not balloon during design basis, and beyond design basis accidents, it would not block the flow designed to cool an overheated core.

b. Accident tolerance - oxidation and hydrogen release - In addition to the avoidance of ballooning and flow blockage, the $\mathrm{SiC}$ clad would not react exothermically and release extensive volumes of hydrogen during design basis and beyond design basis accident, thus exacerbating the rapid heatup of the core, and creating the potential for hydrogen explosions. Tests have been performed of the SiC up to $1400^{\circ} \mathrm{C}$ in steam, to verify this characteristic.

c. Resistance to Fretting and Debris Induced Clad failures - SiC is one of hardest materials found in nature, and is used as an abrasive in many manufacturing industries. As such it could lead to a significant reduction in operational fuel failures in current LWRs that are caused by fretting of the cladding tubes at the grid springs, and debris induced failures at the core inlet.

d. High Burnup Potential and Extended Fuel Cycle Duration - SiC cladding has the potential to extend burnup beyond the current regulatory limit of $62 \mathrm{GWd} / \mathrm{t}$ peak, because it does not become oxidized and embrittled with extended exposure as does advanced zirconium alloys. Exposure tests at MIT for over 3 full power years indicate the potential for 6 to 10 year exposure, depending on the thickness of the environmental barrier layer.

e. High Power Density - Because of its high temperature capability, up to $1500{ }^{\circ} \mathrm{C}$, SiC cladding is likely to survive the brief Departure from Nuclear Boiling (DNB) Events (and similar dryout events with BWRs) that are prohibited with zircaloy cladding, and thus permit higher linear heat ratings and higher power densities. To take advantage of this cladding feature, it will be necessary to couple the cladding with an advanced fuel form, such as annular fuel pellets with a small percentage of the center replaced by void, such that the increased linear heat rating does not lead to excessive fuel temperatures.

One of the main technical challenges associated with the use of SiC cladding is related to its fabrication; the processes should indeed be greatly improved to allow for the about 35 to $55 \mathrm{~km}$ of cladding necessary per GWe-y (standard $\mathrm{UO}_{2}$ fuel burnup of between 50 and $80 \mathrm{GWd} / \mathrm{t}$ ) to be produced at a reasonable cost. The corresponding mass of $\mathrm{SiC}$ would be between about 1.7 and 2.8 tons per GWe-y (considering a SiC wall thickness similar to that of the standard zircaloy and a SiC density about half that of zircaloy). The other challenge is developing a robust end joint design including a bond agent to seal the joint between the fuel rod end cap and the clad tube in order to ensure hermeticity of the fuel-clad system [6.2]. During early 2010, a number of different bond agents were irradiated in the MIT research reactor and five of six test specimens failed the test. 
The impact of moving to $\mathrm{SiC}$ cladding on the required fuel enrichment will be heavily dependent on the specifics of the chosen fuel design. Causal factors will be any displaced fuel due to a thicker cladding, or the possible use of an annular fuel form in order to limit the increase in fuel peak temperature due to the low thermal conductivity of $\mathrm{SiC}$ compared to that of zircaloy. Note that although non-irradiated $\mathrm{SiC}$ has excellent thermal conductivity, it deteriorates very rapidly with irradiation and saturates at about 2-8 W/m-K [6.7] whereas that of zircaloy is typically between $15-20 \mathrm{~W} / \mathrm{m}-\mathrm{K}$. In any event, preliminary estimates indicate a range from essentially no change up to an increased enrichment of $\sim 0.5$ w/o required [6.3].

For example, considering a SiC clad having the same wall thickness as the standard zircaloy clad (570 microns) and an annular $\mathrm{UO}_{2}$ fuel pellet having a central hole occupying $10 \%$ of the volume, the U235 enrichment is about $0.25 \mathrm{w} / \mathrm{o}$ higher than that in the reference $\mathrm{UO}_{2} /$ zircaloy fuel [6.4] for the same cycle length (power uprates, though a possibility, are not considered here). Hence, the U-235 enrichment of the $\mathrm{UO}_{2} / \mathrm{SiC}$ fuel would be about $4.45 \%$ for the $3 \times 18$ month fuel management compared to $4.2 \%$ for the reference $\mathrm{UO}_{2} /$ zircaloy fuel. However, since the $\mathrm{UO}_{2} / \mathrm{SiC}$ fuel contains $10 \%$ less uranium the burnup is also $10 \%$ higher, i.e. $55 \mathrm{GWd} / \mathrm{t}$ vs. $50 \mathrm{GWd} / \mathrm{t}$ for the reference $\mathrm{UO}_{2} /$ zircaloy fuel. Consequently, the $\mathrm{UO}_{2} / \mathrm{SiC}$ fuel requires only about 20 tons of LEU (4.45 w/o) per GWe-y compared to 22 tons of LEU (4.2 w/o) for the reference $\mathrm{UO}_{2}$ /zircaloy fuel. Both cases require about the same amount of natural uranium (190 tons per GWe-y) and SWU (138 kSWU per GWe-y).

As mentioned above, an important feature of the use of $\mathrm{SiC}$ cladding is the possibility to reach higher burnups by leaving the fuel assemblies longer in the core. For example, increasing the number of 18-month cycles from three (current practice) to four or five would increase the average burnup at discharge from the current $50 \mathrm{GWd} / \mathrm{t}$ to about 65 to $85 \mathrm{GWd}$ /t. Similar burnups could be obtained by increasing the cycle length from 18 to 24 months and leaving the assemblies in the core for three or four cycles. The following paragraphs address the particular aspect of high burnup fuels [6.5].

Beyond an average standard $\mathrm{UO}_{2}$ fuel discharge burn-up of approximately $60 \mathrm{GWd} / \mathrm{t}$, the initial enrichment for PWRs will be in excess of the $5.0 \mathrm{w} / \mathrm{o}$ licensing limit of current fuel fabrication plants. The $5.0 \mathrm{w} / \mathrm{o}$ threshold is also important for fresh fuel transport criticality safety. Average assembly burnups of $85 \mathrm{GWd} / \mathrm{t}$ could be attained in PWRs with enrichments of approximately $7.5 \mathrm{w} / \mathrm{o}$. Fresh assemblies with higher enrichments will require adaptation of fuel enrichment facilities, transport casks, pool and dry storage facilities at nuclear power plants and repositories. Note that there are indications that the situation regarding the $5 \mathrm{w} / \mathrm{o}$ limit may soon change. Indeed, the Georges Besse 2 gas centrifuge plant in France, inaugurated in December 2010, is designed for up to $6.0 \mathrm{w} / \mathrm{o}$, with the possibility of extension to $8.0 \mathrm{w} / \mathrm{o}$ without requiring re-licensing [6.5].

The higher decay heat output and neutron emissions of high burn-up fuel, along with the possibility of the used fuel having a higher reactivity, has possible implications for used fuel storage pond 
operations and criticality assessments. At discharge, the decay heat loading and neutron emission from high burn-up fuel will diminish more slowly, with possible repercussions for subsequent transport of the fuel to other storage locations or reprocessing.

An indisputable benefit of high burn-ups is that there is a proportional reduction in the mass of used fuel discharged. For example it goes down from about 22 tons per GWe-y to 13 tons per GWe-y when the burnup is increased from 50 to $85 \mathrm{GWd} / \mathrm{t}$. A need to store used fuel for longer periods also has implications beyond just reactor operation in that it may delay final emptying of the fuel ponds after reactor closure and therefore delay the start of pond decommissioning operations.

The high minor actinide inventory of high burn-up fuels, which causes enhanced decay heat and neutron emissions, has possible repercussions for reprocessing plants and may require changes of design and/or operating procedures. An additional factor is the incorporation of high-level waste in glass, which in current plants is limited by neutron emissions; at high burn-ups the increased inventory of Cm-244 (respectively, about 80 and $200 \mathrm{~g}$ per tons $\mathrm{HM}$ at 50 and $85 \mathrm{GWd} / \mathrm{t}$ ) may reduce incorporation rates and lead to increased volumes of vitrified waste. The isotopic make-up of plutonium recovered from high burn-up fuel will contain fewer fissile isotopes, which has particular implications for plutonium recycling in thermal reactors (higher plutonium content necessary in MOX fuel assemblies).

High average discharge burn-ups require high average U-235 enrichments in the core and this, in turn, reduces the reactivity worths of absorbing materials such as boron, gadolinia and of neutron absorbing materials used in control rods. For PWRs this implies higher critical boron concentrations and/or higher burnable poison loadings, while for BWRs higher burnable poison loadings, possibly supplemented by and increased control rod insertion will be needed.

In PWRs the core boron injection system may need to be re-evaluated to test if it meets more onerous requirements due to the higher reactivity of high burn-up fuel. At the same time, the differential in reactivity between the fresh fuel and the partly burnt fuel in the core increases, leading to a tendency for higher radial power peaking factors.

Cores containing high burn-up fuels will have different safety and transient characteristics that will need to be assessed against the various safety criteria. Such changes may require the safety analyses to be re-assessed.

In addition to increased burnups, $\mathrm{SiC}$ could also potentially allow power uprates, which would directly increase the operator's revenue. Generally the smaller power uprates (less than approximately $2 \%$ ) can be achieved through improved operational performance and analytical tools such as the improved performance of plant equipment both on the primary and secondary side, protection and monitoring system, operator performance, etc and also by improved state of the art analysis codes and the technical insights, without compromising licensing margins [6.6]. 
Greater power uprates (less than approximately 7\%) may require significant hardware changes such as refurbishment or replacement of equipment contributing considerably to power uprates without violating any regulatory acceptance criteria. A detailed cost- benefit analysis needs to be performed, considering implications on various aspects such as safety analysis deterministic and probabilistic, handling of additional waste, used fuel storage facility or reprocessing, environmental impact, etc.

Extended uprates, up to $20 \%$, may be limited by critical reactor components such as reactor vessel, pressurizer, primary heat transport systems, piping etc., or secondary components such as turbine or main generator.

Timing of small power uprates can generally be considered well before the plant reaches the end of the initial license period. This will not require refurbishment or replacement of very capital intensive equipment and operator readjustment to the new operating procedures consequent to the replacement. Also return on investment by the utility will not be affected.

Greater power uprates may be worth consideration when the plant is due for regular periodic safety assessment or at the end of its initial license period when the utility is looking for license renewal. This align well with cost benefit considerations. For example, the cost for analyses and hardware modifications as well as the required outage time for the modifications should be carefully analyzed.

Regarding the economics of SiC clad, preliminary analyses can be found in [6.3] and [6.4]. The following paragraphs try to summarize these analyses. The cost of zirconium alloy cladding in current oxide fuel bundles is roughly $\$ 20 \mathrm{k}$ to $\$ 30 \mathrm{k}$ per assembly. An estimation of the cost incurred by the fabrication of $\mathrm{SiC}$ cladding mentioned in [6.3] is $\sim \$ 900 \mathrm{k}$ per assembly, representing an overall increase of the cost of a fuel assembly of about $75 \%$, i.e. from about $\$ 1.15 \mathrm{M}$ to $\$ 2.0 \mathrm{M}$ (see Table 6.1).

Table 6.1. Comparison between the cost of PWR oxide and SiC clad PWR assemblies in an AP-1000 core [6.3]

\begin{tabular}{|l|c|c|c|c|}
\hline & Unit Cost & $\begin{array}{c}\text { AP-1000 } \\
17 \times 17 \\
\text { Assembly } \\
\text { Cost }[\mathrm{k} \$\end{array}$ & $\begin{array}{c}\text { SiC Clad } \\
\text { Fuel Cost } \\
\text { Ratio }\end{array}$ & $\begin{array}{c}\text { SiC Clad } \\
\text { Fuel Cost } \\
{[\mathrm{k} \$]}\end{array}$ \\
\hline $\begin{array}{l}\text { Uranium } \\
\text { Mining/Milling }\end{array}$ & $75[\$ / \mathrm{kgNatU}]$ & 462 & 1.023 & 473 \\
\hline Conversion & $10[\$ / \mathrm{kgNatU}]$ & 62 & 1.023 & 63 \\
\hline Enrichment & $110[\$ / \mathrm{SWU}]$ & 427 & 1.138 & 486 \\
\hline DU Disposal & $11[\$ / \mathrm{kgDU}]$ & 62 & 1.060 & 66 \\
\hline Fuel/Clad Fabrication & $250[\$ / \mathrm{kgLEU}]$ & 135 & 6.9 & 930 \\
\hline Total & & 1147 & & 2018 \\
\hline
\end{tabular}

Therefore, the increase in cost associated with fabrication of the new SiC-based clad will be the main driver in the overall fuel cost surpassing all other items in magnitude. In the estimate, it was assumed that the current nuclear grade $\mathrm{SiC}$ material was utilized (such as Nicalon Type-S fibers.) 
Currently, alternative methods that may be less costly are being investigated. Additional irradiation testing of $\mathrm{SiC}$ materials fabricated via these alternative techniques will be required to determine applicability in a reactor environment.

A detailed comparative economic analysis of PWR cores using $\mathrm{SiC}$ or $\mathrm{Zr}$ cladding has been carried out by EPRI in 2011 [6.4]. The authors considered the fabrication cost of SiC cladding as a parameter that was varied. They concluded that the increase in cycle length, burnup and, potentially, power output that could be obtained with $\mathrm{SiC}$ cladding would bring about such an increase in revenue for the operator that "it would not be offset by any reasonable fabrication cost increase due to use of silicon carbide". However, from the tables and figures presented in [6.4], it seems that the factor 7 on the fabrication cost between $\mathrm{Zr}$ and $\mathrm{SiC}$ clad fuel (see Table 6.1 above) assemblies would be more than what the authors considered reasonable. For example, considering an increase of the cycle length as well as of the burnup, the break-even point seems to somewhat between a factor of 3 and 4 . The break-even point is even higher when power uprates are taken into account.

\section{Steel Cladding}

Similarly to $\mathrm{SiC}$, the use of steel in cladding designs could also improve performance in certain areas under LWR core conditions, particularly under conditions where properties of zirconium based alloys could be significantly degraded, such as loss of coolant accidents. In particular, the heat release in the steel-steam reaction is about a factor of 20 lower than that for the zirconium-steam reaction [7.1] which would significantly reduce the rate of cladding temperature rise during a large break loss of coolant accident. Furthermore, the higher strength of stainless steel would also result in less distortion if the fuel was exposed to the high temperatures possible during such an accident. This aspect is important in maintaining a coolable geometry. On the other hand the melting point of stainless steels is about $400^{\circ} \mathrm{C}$ lower than that of zircaloy (respectively about $1450^{\circ} \mathrm{C}$ and $1850^{\circ} \mathrm{C}$ ).

A 1982 EPRI report [7.2] summarizes the experience accumulated with stainless steel clad fuel rods in PWRs and BWRs. A total of about 600,000 stainless steel clad fuel rods (all 304SS) were irradiated up to 1981 in a number of PWRs, both in the US and abroad. In addition, about 23,000 rods were irradiated in the only BWR operating with stainless steel clad. Overall the performance record of stainless steel clad fuel rods in PWRs has been excellent but the stainless steel clad failure in early General Electric BWRs is the reason that this type of fuel was discontinued. Burnups as high as $46 \mathrm{GWd} / \mathrm{t}$ assembly average have been obtained and $70 \mathrm{GWd} / \mathrm{t}$ rod average on individual experimental rods in the materials testing reactor BR-2. Reference [7.2] also mentions that detailed performance comparisons between zircaloy and stainless steel clad fuel rods were performed for loss of coolant accident conditions and that the number of stainless steel rods predicted to rupture was consistently significantly lower than 
the zircaloy rods. However, for accidents of the severity of TMI-2, they concluded that stainless steel offered no apparent advantages over zircaloy because of the rapid oxidation of stainless steel at temperature above $1300^{\circ} \mathrm{C}$ along with its low strength near the melting point. Note that these conclusions were reached with the historic 304SS austenitic stainless steels whereas current studies tend to favor advanced ferritic stainless steel such as the FeCrAl alloy. The extent to which these conclusions apply to these more advanced steels will need to be determined.

Regarding reactor operation, with the exception of the control rod worth and soluble boron worth, the reactivity coefficients of zircaloy and steel clad cores are very similar if the geometry of the fuel assemblies is the same [7.2]. The reason for the reduced control rod worth and soluble boron worth is the harder neutron spectrum in the steel clad core brought about by the thermal neutron captures in steel as well as by the higher fissile enrichment (see below). With reduced control rod worth and soluble boron worth, the impact on reactor operation, reactivity shutdown margins and on the outcome of transients will need to be re-evaluated.

Tritium diffusion through stainless steel cladding is significantly greater than through zircaloy cladding, resulting in significantly higher coolant tritium inventories for stainless steel clad cores [7.2]. Indeed, whereas the percentage of tritium released is typically between $0.1 \%$ and $1 \%$ for zircaloy cladding, it may be on the order of 50\% for stainless steel cladding, hence, potentially requiring additional controls to minimize the release. The use of tritium getters, or barriers, in the fuel rod could serve that function. The impact on the cost of operating the reactor will need to be evaluated.

The high thermal neutron absorption of steel will increase uranium enrichment requirements. Recent calculations [7.3] performed considering a standard $\mathrm{UO}_{2} \mathrm{PWR} 17 \times 17$ assembly geometry with an advanced nickel-free steel refered to as $\mathrm{FeCrAl}$ (about 75 w/o Fe, 20 w/o Cr and 5 w/o Al) show that the uranium enrichment must be increase by about $1 \mathrm{w} / \mathrm{o}$ in order to maintain a constant cycle length. With a stainless steel containing about $20 \%$ of nickel (310SS) the increase is even higher ( $\sim 1.5 \mathrm{w} / \mathrm{o})$.

Considering a $1 \mathrm{w} / \mathrm{o}$ increase in enrichment, i.e. $5.2 \mathrm{w} / \mathrm{o}$ instead of $4.2 \mathrm{w} / \mathrm{o}$ for the reference $\mathrm{UO}_{2}$ $3 \times 18$ months fuel management, the amount of natural uranium and SWU necessary to fabricate the 22 tons of LEU per GWe-y increases by about, respectively, 24\% (from about 190 tons to about 235 tons per GWe-y) and 34\% (from about $138 \mathrm{kSWU}$ to $184 \mathrm{kSWU}$ ). Note that the uranium present in the steel clad used fuel assemblies will also contain more residual U-235 than the reference zircaloy clad assemblies; if this uranium was to be recycled it would minimize the increase in natural uranium requirement.

Another possible approach, to compensate for the additional neutron absorption brought about by steel, is to minimize the clad thickness and increase the fuel pellet diameter (keeping the clad outer diameter constant) which implies an increase of the fuel mass inside the core. A full evaluation of the potential optimized steel clad thickness would need to consider corrosion, grid-to-rod fretting, and other clad reliability issues, however, the ability to use thinner cladding is anticipated because of the higher 
strength of the steel and because of its enhanced corrosion performance (retained strength with operation). Reduction in cladding thickness from the reference value of 570 microns down to 300 microns, with its associated increase in fuel pellet diameter, is necessary to maintain the current cycle lengths using the same enrichment as the reference zircaloy clad assembly [7.3].

Decreasing the clad thickness by 270 microns allows increasing the pellet diameter by 540 microns, i.e. the pellet diameter increases from $8.2 \mathrm{~mm}$ to $8.74 \mathrm{~mm}$; the corresponding increase of the fuel volume is about $14 \%$. In this case, the fuel enrichment and cycle length are the same as those of the reference zircaloy clad core, but, since the fuel mass is about $14 \%$ higher than the reference core, the burnup will consequently be lower by a factor 1.14 (i.e. $44 \mathrm{GWd} / \mathrm{t}$ instead of $50 \mathrm{GWd} / \mathrm{t}$ ). Hence the mass of LEU to fabricate will increase from the reference value of 22.1 tons per GWe-y to $22.1 \times 1.14=25.2$ tons per GWe-y and, as a result, the mass of natural uranium and SWU necessary per GWe-y increase by the same $14 \%$. An approximately $0.5 \mathrm{w} / \mathrm{o}$ increase in enrichment would allow increasing the cycle length from the reference 18 months to about 20.5 months with a corresponding increase in burnup from 44 to $50 \mathrm{GWd} / \mathrm{t}$. In that case the mass of LEU ( $4.7 \mathrm{w} / \mathrm{o})$ to fabricate is 22.1 tons per GWe-y and, as a result, the mass of natural uranium and SWU necessary per GWe-y increase by respectively 13 and $17 \%$ relative to the reference 22.1 tons of LEU ( $4.2 \mathrm{w} / \mathrm{o})$.

The amount of steel cladding to be fabricated amounts to about 55-63 km per GWe-y $\left(\mathrm{UO}_{2}\right.$ burnup of about 44-50 GWd/t) which corresponds to about 3.1-3.5 tons per GWe-y (considering a steel wall thickness of about half that of the standard zircaloy and a steel density about $10 \%$ higher than that of zircaloy).

Regarding the back-end of the fuel cycle, if only the cladding is modified, the impact on the characteristics of the used fuel assemblies (i.e. plutonium, minor actinides and fission products) will be very limited. Regarding the long term storage of steel clad assemblies, a 1996 EPRI report [7.4] mentions that the US and foreign experience included up to 25 years (1970 to 1995) of visual observation and radiation monitoring in pool storage. In addition, a limited amount of nondestructive and metallurgical examinations of steel clad assemblies after reactor service and periods of pool storage with observations for periods of five years indicated that the cladding was not degrading.

\section{Zircaloy Cladding with Coating}

Coating consists in applying a thin layer of material on zircaloy (Fig. 8.1) with the objective to minimize or significantly delay oxidation of the cladding, thus reducing the amount of hydrogen generated and the oxygen ingress into the cladding during transient conditions, as well as decrease cladding oxidation and hydrogen pickup during normal operation. 
MAX phase ceramic coatings are ideal candidates for this purpose [8.1]. The MAX phases have the general formula: $\mathrm{M}_{\mathrm{n}+1} \mathrm{AX},(\mathrm{MAX})$ where $\mathrm{n}=1$ to $3, \mathrm{M}$ is an early transition metal, $\mathrm{A}$ is an A-group (mostly IIIA and IVA, or groups 13 and 14) element and $\mathrm{X}$ is either carbon and/or nitrogen. They exhibit excellent resistance to oxidation and corrosion, as well as tolerance to mechanical damage. Furthermore, they conduct heat like metals. Out of more than 60 known MAX phases, three candidates were selected for a preliminary evaluation: $\mathrm{Ti}_{3} \mathrm{AlC}_{2}, \mathrm{Ti}_{2} \mathrm{AlC}$, and $\mathrm{Nb}_{2} \mathrm{AlC}$. Besides $\mathrm{MAX}$ phases, titanium aluminum nitride (TiAlN) is also under consideration. Like MAX phases, TiAlN presents noticeable oxidation resistance and hardness, but is relatively inefficient in conducting heat.

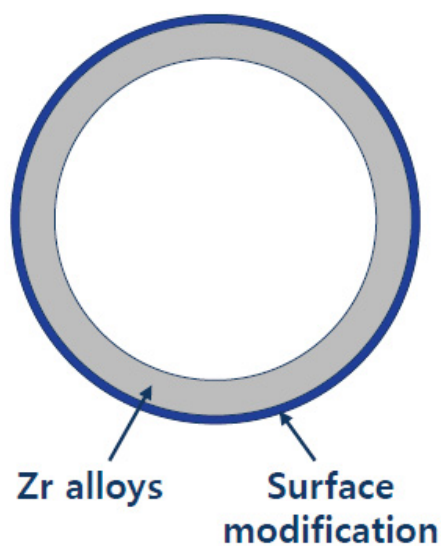

Figure 8.1 Illustration of the coating concept

To evaluate the impact of such coatings on fuel enrichment, it was assumed that fuel dimensions remain as in the reference design and the coating was added to the outer side of the clad. A reference $\mathrm{UO}_{2}$ and zirconium-alloy fuel was assumed $4.5 \mathrm{w} / \mathrm{o}$ enriched and Zircaloy-4 was set as the standard cladding material. The manufacturing processes of coating as well as the necessary thickness are still both being investigated; hence, Table 8.1 presents the enrichments necessary to maintain the same cycle length as the reference fuel with different coating materials and thicknesses. It shows that the impact on the enrichment can go up to +0.4 w/o, i.e. from the reference $4.5 \mathrm{w} / \mathrm{o}$ to $4.9 \mathrm{w} / \mathrm{o}$, for a coating thickness of 100 microns. In that case, the amount of natural uranium and SWU necessary to fabricate the fuel increase by, respectively about $9 \%$ and $12 \%$.

It will be important that the coating processes allow for the about $55 \mathrm{~km}$ of cladding necessary per GWe-y (standard $\mathrm{UO}_{2}$ fuel burnup of $50 \mathrm{GWd} / \mathrm{t}$ ) to be produced at a reasonable cost. Note that since the fabrication cost of zirconium alloy cladding in current oxide fuel bundles is roughly $\$ 20 \mathrm{k}$ to $\$ 30 \mathrm{k}$ per assembly, i.e. only about $2 \%$ of the total cost of an assembly, even a doubling of the cost of the cladding would have only a limited impact on the overall cost of the assembly. 
Table 8.1 Fuel enrichment that matches the reference cycle length as a function of coating composition and thickness [8.2]

\begin{tabular}{lccc}
\hline \multirow{2}{*}{ Coating } & \multicolumn{3}{c}{ Thickness, $\mu \mathrm{m}$} \\
\cline { 2 - 4 } & 10 & 50 & 100 \\
\hline $\mathrm{Ti}_{3} \mathrm{AlC}_{2}$ & 4.53 & 4.70 & 4.90 \\
$\mathrm{Ti}_{2} \mathrm{AlC}$ & 4.53 & 4.68 & 4.84 \\
$\mathrm{Nb}_{2} \mathrm{AlC}$ & 4.52 & 4.64 & 4.80 \\
$\mathrm{TiAlN}$ & 4.53 & 4.68 & 4.86 \\
\hline
\end{tabular}

Because only the cladding is modified, the impact on the characteristics of the used fuel assemblies (i.e. plutonium, minor actinides and fission products) will be very limited. Power uprates and increased fuel burn-up are not likely either to be achieved via coatings since the base material would have the same limits as current cladding [8.1]. Hence, granted the behavior of the coating under PWR normal and accidental conditions is shown to be satisfactory, this concept should have only minimal impact on either the front-end or the back-end of the fuel cycle since only the clad is involved.

Coated zirconium alloys should be considered as a potential back-up technology that could be developed in a shorter time frame than ceramic cladding should the investigated ceramic cladding options fail to demonstrate the desired performance enhancements.

Among the open issues related to the coating concepts are the following [8.1]:

- Determine how much coating will / should remain on the rod during normal handling, installation, normal operation and accident conditions.

- If coating flakes off due to erosion, corrosion or differential thermal expansion processes, determine how the coating debris may affect the reactor during operation (assessed via corrosion/erosion tests, chemical compatibility tests, and computational analyses)

- Identify any non-desirable properties at the cladding / fuel interface (assessed via inter-diffusion, porosity tests)

- The ability to fully, consistently coat the cladding rod and endcaps and to evaluate the integrity and thickness of a coating may be exceedingly difficult. Coating techniques and evaluation tools must address this issue.

\section{Molybdenum cladding}

Molybdenum is a high strength material which possesses a high thermal conductivity and a low coefficient of expansion which makes it attractive for cladding applications. Due to its high melting point of $2620^{\circ} \mathrm{C}$ (melting point of zircaloy is $1850^{\circ} \mathrm{C}$ ), molybdenum retains its strength and creep resistance even at high temperatures. Furthermore, its resistance to steam corrosion is fairly good up to $635^{\circ} \mathrm{C}$; experimental data show that it would take in excess of 25 and 17 hours to oxidize through 30 mils of, 
respectively, molybdenum and zirconium [9.1]. On the other hand, the corrosion resistance of unprotected molybdenum to high purity, high temperature water is poor. Thus for reactor applications, molybdenum, more likely, will require a coating which resists degradation by reactor water. The figure below shows the example of a thin-wall molybdenum alloy tube protected by zirconium alloy, or advanced steel on the outside surface. Molybdenum's inner surface could also be protected by a soft zirconium alloy or others as an option. Such concept may achieve accident tolerance to $1200-1500^{\circ} \mathrm{C}$ [9.1].

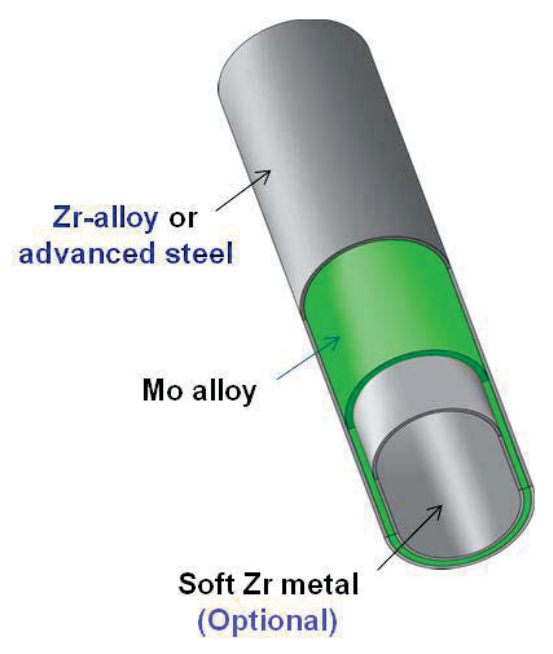

Figure 9.1 Illustration of a possible molybdenum-based cladding concept [9.2]

Unlike zircaloy or steel, molybdenum has a relatively high brittle-to-ductile transition temperature ${ }^{b}$ which requires that fabrication be performed at elevated temperatures [9.1]. The impact on fabrication cost will need to be evaluated. Furthermore, molybdenum can be worked in air only to about $540{ }^{\circ} \mathrm{C}$ without difficulty. Above this temperature it must be protected or it will rapidly oxidize.

The high thermal neutron absorption of molybdenum will increase uranium enrichment requirements to an extent that will depend on its thickness. Preliminary calculations [9.3] performed considering a standard $\mathrm{UO}_{2}$ PWR $17 \times 17$ assembly geometry with a molybdenum clad having the same wall thickness as that of the reference zircaloy clad show that the uranium enrichment must be increased by about $2.6 \mathrm{w} / \mathrm{o}$ in order to maintain a constant cycle length. Using a molybdenum wall thickness equal to only half that of the standard zircaloy clad (the other half being a zircaloy alloy, see Fig. 9.1), the impact on the uranium enrichment would be also about only half, i.e. about $+1.3 \mathrm{w} / \mathrm{o}$.

\footnotetext{
${ }^{\mathrm{b}}$ If molybdenum is heated above a certain temperature then it loses its brittleness and becomes ductile. This temperature that is required to bring about the transition from brittleness to ductility is known as the brittle-to-ductile transition temperature. It depends on various factors including the chemical composition and level of cold working of the metal and can be as high as a few hundred degrees Celsius in the case of molybdenum. Forming and machining of molybdenum, and refractory metals in general, must be done above the brittle-ductile transition temperature to ensure that the sheet can be safely worked without risk of fissuring.
} 
Considering an increase in enrichment of between 1.3 and 2.6 w/o, i.e. 5.5 to 6.8 w/o instead of $4.2 \mathrm{w} / \mathrm{o}$ for the reference $3 \times 18$ months fuel management, the amount of natural uranium and SWU necessary to fabricate the 22 tons of LEU per GWe-y increase by about, respectively, 32 to $65 \%$ (from about 190 tons to about 250-315 tons per GWe-y) and 44 to $89 \%$ (from about 138 kSWU to about 199260 kSWU per GWe-y).

Hence, it seems probable that the use of molybdenum clad will yield higher enrichment than the 5.0 w/o licensing limit of current fuel fabrication plants and will, consequently, require adaptation of fuel enrichment facilities. Note, however, that the uranium present in the molybdenum clad used fuel assemblies will also contain more residual U-235 (about $2.4 \mathrm{w} / \mathrm{o}$ in the case of $6.8 \mathrm{w} / \mathrm{o}$ initial enrichment [9.3]) than the reference zircaloy clad assemblies; if this uranium was to be recycled it would minimize the increase in natural uranium requirement. Furthermore, there are indications that the situation regarding the 5 w/o limit may soon change. Indeed, the Georges Besse 2 gas centrifuge plant in France, inaugurated in December 2010, is designed for up to $6.0 \mathrm{w} / \mathrm{o}$, with the possibility of extension to $8.0 \mathrm{w} / \mathrm{o}$ without requiring re-licensing [9.4].

The amount of molybdenum cladding to be fabricated amounts to about $55 \mathrm{~km}$ per GWe-y (standard $\mathrm{UO}_{2}$ fuel burnup of $50 \mathrm{GWd} / \mathrm{t}$ ) which corresponds to about 4.5 tons per GWe-y (considering a molybdenum wall thickness of about half that of the standard zircaloy and a molybdenum density about $55 \%$ higher than that of zircaloy). Since the isotope Mo-95 ( 15.9\% in molybdenum) is responsible for most of the neutron absorption in molybdenum, using molybdenum depleted in this particular isotope would eliminate, or at least mitigate, the impact on the uranium enrichment. The added cost coming from depleting molybdenum versus the benefit coming from lower uranium enrichment would need to be analyzed.

From these numbers, it comes that depleting 4.5 tons of molybdenum per GWe-y so that it contains almost no Mo-95 could potentially bring about an economy of about 60 tons of natural uranium per GWe-y (190 tons instead of 250 tons) and of 61 kSWU per GWe-y (138 kSWU instead of 199 $\mathrm{kSWU}$ ). If we consider $\$ 85 / \mathrm{kg}-\mathrm{NU}$ for uranium mining, milling and conversion as well as $\$ 110 / \mathrm{SWU}$ for enrichment (see Table 2.1), it comes that the potential economy is about $\$ 11.8 \mathrm{M}$ per GWe-y. Hence, the break-even cost of depleting molybdenum seems to be around $\$ 2.6 \mathrm{k}$ per $\mathrm{kg}$ of molybdenum $(\$ 11.8 \mathrm{M}$ divided by $4500 \mathrm{~kg}$ of molybdenum); below this value, the cost of depleting molybdenum is more than compensated by the economies on natural enrichment mining, milling, conversion and enrichment, whereas above this value it is not the case.

As discussed with steel clad, the control rod worth and soluble boron worth will be lower than those of the reference zircaloy clad core because of the harder neutron spectrum brought about by the thermal neutron captures in (natural) molybdenum as well as by the higher fissile enrichment. With reduced control rod worth and soluble boron worth, the impact on reactor operation, reactivity shutdown 
margins and on the outcome of transients will need to be re-evaluated. If depleted molybdenum is used instead of natural molybdenum these issues would be largely mitigated, if not totally eliminated.

\section{Conclusions}

Various LWR fuel concepts referred to as enhanced accident tolerant fuels are currently under development in the US and throughout the world. These fuels, in comparison with the standard zircaloy$\mathrm{UO}_{2}$ system currently used by the LWR industry, should be designed such that they tolerate loss of active cooling in the core for a longer time period (depending on the LWR system and accident scenario) while maintaining or improving the fuel performance during normal operations, operational transients, and design-basis events. This report presents a preliminary systems analysis related to most of these concepts. The potential impacts of these innovative LWR fuels on the front-end of the fuel cycle, on the reactor operation and on the back-end of the fuel cycle are succinctly described without having the pretension of being exhaustive. Since the design of these various concepts is still a work in progress, this analysis can only be preliminary and could be updated as the designs converge on their respective final version.

Severe accidents involve a suite of complex phenomena, and care should be exercised to delineate the full extent of accident tolerance of these advanced fuel/cladding concepts as well as their impact on reactor operation in order to be able to make informed decisions regarding future investments. This step is particularly important because most of these enhanced accident tolerant fuels will probably result in higher fuel assembly fabrication costs caused, for example, by higher natural uranium and separating work unit (SWU) requirements, or by the isotopic enrichment of materials such as molybdenum or nitrogen, or by the fuel form itself (e.g. TRISO). As in any complex engineering application, optimal properties cannot be consistently obtained from any one concept over the full range of parameters desired. 


\section{References}

[1.1] Advanced Fuels Campaign Execution Plan, Fuel Cycle Research \& Development Report FCRDFUEL-2011-000105 (INL/EXT-10-18954, Rev. 2), October 31, 2012.

[1.2] Steven L. Hayes Kristine E. Barrett, Irradiation Testing of Accident Tolerant Fuels in the ATR (ATF-1 Test Series), PLN-4444

[1.3] Nuclear Fuel Behavior in Loss-of-coolant Accident (LOCA) Conditions - State-of-the-art Report, NEA No. 6846 (2009)

[1.4] Nuclear Fuel Behavior under Reactivity Initiated Accident (RIA) Conditions - State-of-the-art Report, NEA No. 6847 (2010)

[1.5] K.A. Terrani, S.J. Zinkle, L.L. Snead, “Advanced Oxidation-Resistant Iron-Based Alloys for LWR Fuel Cladding", Journal of Nuclear Materials (2013)

[2.1] Nicholas R. Brown, Hans Ludewig, Arnold Aronson, Gilad Raitses, Michael Todosow, "Neutronic evaluation of a PWR with fully ceramic microencapsulated fuel. Part I: Lattice benchmarking, cycle length, and reactivity coefficients", Ann. Nucl. Energy (2013)

[2.2] R. Sonat Sen, Michael A. Pope, Abderrafi M. Ougouag, Kemal O. Pasamehmetoglu, "Assessment of possible cycle lengths for fully encapsulated microstructure fueled light water reactor concepts", Nuclear Engineering and Design 255 (2013) 310-320

[2.3] R. Sonat Sen, B. Boer, A.M. Ougouag, J.D. Bess, M.A. Pope, “Advanced Fuels for LWRs: FCM and Related Concepts FY 2012 Final Report", INL/EXT-12-27129, September 2012

[2.4] Jeffrey J. Powers, "Fully Ceramic Microencapsulated (FCM) Replacement Fuel for LWRs", ORNL/TM-2013/173, May 2013

[2.5] Spent Fuel Reprocessing Options, IAEA-TECDOC-1587 (2008)

[2.6] Shannon M. Bragg-Sitton, "Light Water Reactor Sustainability Program - Advanced LWR Nuclear Fuel Cladding System Development Technical Program Plan”, INL/MIS-12-25696, Revision 1, Dec. 2012

[2.7] Assessment of High Temperature Gas-Cooled Reactor (HTGR) Capital and Operating Costs, TEV1196 Revision 1, Sept. 2012

[2.8] "Management of Waste Containing Tritium and Carbon-14", IAEA Technical Reports Series 421

[3.1] WD Bennett et al, "FY-13 Status Report for the U-Mo Fuel Concept", FCRD-FUEL-2013-000326, PNNL-22730 
[3.2] Personal communication, Sonat Sen, Reactor Physics Analysis \& Design Dept, Idaho National Laboratory

[4.1] Paul A. Lessing, "Oxidation Protection of Uranium Nitride Fuel Using Liquid Phase Sintering”, INL/EXT-12-24974 (2012)

[4.2] Personal communication, Sonat Sen, Reactor Physics Analysis \& Design Dept, Idaho National Laboratory

[5.1] Personal communication, Sonat Sen, Reactor Physics Analysis \& Design Dept, Idaho National Laboratory

[6.1] Herbert Feinroth (CEO, Ceramic Tubular Products LLC), "Silicon Carbide Triplex Nuclear Fuel Cladding An Alternative to Zircaloy That Avoids Severe Core Damage During Accidents", Presentation to the Israel Nuclear Society, February 21, 2012, http://www.ctpusa.com/papers/SiC\%20Cladding\%20-\%20Israel\%20NucSoc\%20Mtg.Feb2012.pdf

[6.2] Kristine Barrett, Shannon Bragg-Sitton, Daniel Galicki, "Nuclear Fuel Cladding System Development Trade-off Study", INL/EXT-12-27090, Sept. 2012

[6.3] Shannon M. Bragg-Sitton, "Light Water Reactor Sustainability Program - Advanced LWR Nuclear Fuel Cladding System Development Technical Program Plan”, INL/MIS-12-25696, Revision 1, Dec. 2012

[6.4] K. Yueh, M. S. Kazimi, "PWR Cores with Silicon Carbide Cladding” EPRI-1022908 (2011)

[6.5] Very high Burn-ups in Light Water Reactors, NEA No. 6224 (2006)

[6.6] Implications of power uprates on safety margins of nuclear power plants, IAEA-TECDOC-1418 (2004)

[6.7] Advanced Ceramic Composites for High-Temperature Fission Reactors, Final NERI Project Report DE-FG03-990281, Pacific Northwest National Laboratory, 2002

[7.1] D. F. Fletcher, B. Turland, and S. Lawrence, "A Review of Hydrogen Production During MeltWater Interaction in LWRs," Nucl. Safety, 33, 514 (1 992).

[7.2] A. Strasser et al, "An Evaluation of Stainless Steel Cladding for Use in Current Design LWRs", EPRI NP-2642 (1982)

[7.3] K.A. Terrani, S.J. Zinkle, L.L. Snead, “Advanced Oxidation-Resistant Iron-Based Alloys for LWR Fuel Cladding”, Journal of Nuclear Materials (2013) 
[7.4] "Evaluation of Expected Behavior of LWR Stainless Steel-Clad Fuel in Long-Term Dry Storage", EPRI TR-106440, Final Report (1996)

[8.1] Lori Braase, Shannon Bragg-Sitton, "Advanced Fuels Campaign Cladding \& Coatings Meeting Summary”, FCRD-FUEL-2013-000114, INL/EXT-13-28628 (March 2013)

[8.2] Rachel A. Shapiro, Ian M. Younker, and Massimiliano Fratoni, "Neutronic performance of accident tolerant fuels", ANS 2013 winter meeting

[9.1] Evaluation of Fuel-Cladding Properties at High Temperatures, EPRI Report NP-5427, 1988

[9.2] EPRI presentation (Heather Feldman, Manager, Thermal-Hydraulics) to the CASL Industry Council Meeting, March 26-27, 2013

[9.3] Personal communication, Sonat Sen, Reactor Physics Analysis \& Design Dept, Idaho National Laboratory

[9.4] Very high Burn-ups in Light Water Reactors, NEA No. 6224 (2006) 


\section{Appendix A}

\section{Estimation of the $\mathrm{C} 14$ production by $(n, p)$ reaction on N14 in an FCM fuelled PWR using UN fuel kernel with natural nitrogen}

- Uranium nitride density: $\mathrm{d}_{\mathrm{UN}}=14.33 \mathrm{~g} . \mathrm{cm}^{-3}$ with $\mathrm{d}_{\mathrm{U}}=13.53 \mathrm{~g} . \mathrm{cm}^{-3}$ and $\mathrm{d}_{\mathrm{N}}=0.8 \mathrm{~g} . \mathrm{cm}^{-3}$

- Nitrogen atom density: $\mathrm{N}_{\mathrm{N}}=(0.8 \div 14) \times 6.022 \times 10^{23}=3.4 \times 10^{22} \mathrm{at}_{\mathrm{N}} \cdot \mathrm{cm}^{-3}$

- Average N14 thermal (n,p) neutron cross section in a PWR spectrum: $\sigma_{\text {th }}(\mathrm{n}, \mathrm{p}) \sim 1$ barn $[\mathrm{A} .1]=10^{-24} \mathrm{~cm}^{2}$ - Average thermal neutron flux in a PWR: $\phi_{\text {th }} \sim 3 \times 10^{13} \mathrm{n} \cdot \mathrm{cm}^{-2} . \mathrm{s}^{-1}$

- N14 $(\mathrm{n}, \mathrm{p})$ reaction rate $=\mathrm{N}_{\mathrm{N}} \times \sigma_{\mathrm{th}}(\mathrm{n}, \mathrm{p}) \times \phi_{\mathrm{th}} \sim 3.4 \times 10^{22} \times 10^{-24} \mathrm{~cm}^{2} \times 3 \times 10^{13} \sim 10^{12} \mathrm{~cm}^{-3} . \mathrm{s}^{-1}$

$\rightarrow$ Hence about $10^{12}$ atoms of $\mathrm{C} 14$ are produced per second and per $\mathrm{cm}^{3}$ of fuel

- A standard $\mathrm{UO}_{2} \mathrm{AP} 1000$ fuel assembly contains $539 \mathrm{~kg}$ of U. If it contains $4.2 \mathrm{w} / \mathrm{o} \mathrm{U}-235$, it comes that there are $22.6 \mathrm{~kg}$ of U-235 per fuel assembly.

- If we consider that a FCM fuel assembly contains the same amount of U-235 as a standard $\mathrm{UO}_{2}$ fuel assembly, it comes that it contains $22.6 \div 0.199 \sim 114 \mathrm{~kg} \mathrm{LEU}(19.9$ w/o U-235) and, consequently, $114 \times$ $(0.8 \div 13.53) \sim 6.7 \mathrm{~kg}$ of nitrogen

- A FCM fuelled AP1000 reactor with 157 fuel assemblies would then contain $157 \times 114=17,898 \mathrm{~kg}$ of LEU which corresponds to a fuel volume of $17,898 \times 10^{3} \div 13.53 \sim 1.3 \times 10^{6} \mathrm{~cm}^{3}$.

- The number of C14 atoms produced per year in a FCM fuelled AP1000 would then be of the order of: $\mathrm{N}_{\mathrm{C} 14} \sim 10^{12} \times 1.3 \times 10^{6} \times 365 \times 24 \times 3600 \sim 4.1 \times 10^{25}$

- C14 half-life $=5730$ years, i.e. $\lambda_{\mathrm{C} 14}=0.693 \div(5730 \times 365 \times 24 \times 3600) \sim 3.8 \times 10^{-12} \mathrm{~s}^{-1}$

- Activity $=\lambda_{\mathrm{C} 14} \times \mathrm{N}_{\mathrm{C} 14} \sim 3.8 \times 10^{-12} \times 4.1 \times 10^{25} \sim 1.6 \times 10^{14} \mathrm{~Bq} \sim 1.6 \times 10^{14} \div 3.7 \times 10^{10} \sim 4324 \mathrm{Ci}$

$\rightarrow$ Hence a FCM fuelled PWR would generate about 4300 Ci of C14 per GWe-y by (n,p) reactions of N14. This is about 2 orders of magnitude more than the total $\mathrm{C} 14$ produced in a standard $\mathrm{UO}_{2}$ fuelled PWR.

[A.1] Estimation of Carbon-14 in Nuclear Power Plant Gaseous Effluents, EPRI Report 1021106, (2010) 


\section{Appendix B}

\section{Estimation of the $\mathrm{C} 14$ production by $(n, p)$ reaction on N14 in a PWR using UN fuel with natural nitrogen}

- Uranium nitride density: $\mathrm{d}_{\mathrm{UN}}=14.33 \mathrm{~g} . \mathrm{cm}^{-3}$ with $\mathrm{d}_{\mathrm{U}}=13.53 \mathrm{~g} . \mathrm{cm}^{-3}$ and $\mathrm{d}_{\mathrm{N}}=0.8 \mathrm{~g} \cdot \mathrm{cm}^{-3}$

- Nitrogen atom density: $\mathrm{N}_{\mathrm{N}}=(0.8 \div 14) \times 6.022 \times 10^{23}=3.4 \times 10^{22} \mathrm{at}_{\mathrm{N}} \cdot \mathrm{cm}^{-3}$

- Average N14 thermal (n,p) neutron cross section in a PWR spectrum: $\sigma_{\mathrm{th}}(\mathrm{n}, \mathrm{p}) \sim 1$ barn $[\mathrm{B} .1]=10^{-24} \mathrm{~cm}^{2}$ - Average thermal neutron flux in a PWR: $\phi_{\text {th }} \sim 3 \times 10^{13} \mathrm{n} \cdot \mathrm{cm}^{-2} . \mathrm{s}^{-1}$

- N14 $(\mathrm{n}, \mathrm{p})$ reaction rate $=\mathrm{N}_{\mathrm{N}} \times \sigma_{\mathrm{th}}(\mathrm{n}, \mathrm{p}) \times \phi_{\mathrm{th}} \sim 3.4 \times 10^{22} \times 10^{-24} \mathrm{~cm}^{2} \times 3 \times 10^{13} \sim 10^{12} \mathrm{~cm}^{-3} . \mathrm{s}^{-1}$

$\rightarrow$ Hence about $10^{12}$ atoms of $\mathrm{C} 14$ are produced per second and per $\mathrm{cm}^{3}$ of fuel

- A standard $\mathrm{UO}_{2} \mathrm{AP} 1000$ fuel assembly contains $539 \mathrm{~kg}$ of U. Because of the higher density of UN fuel, a UN AP1000 fuel assembly would contain about 40\% more LEU, i.e. about $755 \mathrm{~kg}$ and, consequently, $755 \times(0.8 \div 13.53) \sim 44.6 \mathrm{~kg}$ of nitrogen

- A UN fuelled AP1000 reactor with 157 fuel assemblies would then contain $157 \times 755=118,535 \mathrm{~kg}$ of LEU which corresponds to a fuel volume of $118,535 \times 10^{3} \div 13.53 \sim 8.8 \times 10^{6} \mathrm{~cm}^{3}$.

- The number of $\mathrm{C} 14$ atoms produced per year in a UN fuelled AP1000 would then be of the order of: $\mathrm{N}_{\mathrm{C} 14} \sim 10^{12} \times 8.8 \times 10^{6} \times 365 \times 24 \times 3600 \sim 2.8 \times 10^{26}$

- C14 half-life $=5730$ years, i.e. $\lambda_{\mathrm{C} 14}=0.693 \div(5730 \times 365 \times 24 \times 3600) \sim 3.8 \times 10^{-12} \mathrm{~s}^{-1}$

- Activity $=\lambda_{\mathrm{C} 14} \times \mathrm{N}_{\mathrm{C} 14} \sim 3.8 \times 10^{-12} \times 2.8 \times 10^{26} \sim 1.1 \times 10^{15} \mathrm{~Bq} \sim 1.6 \times 10^{14} \div 3.7 \times 10^{10} \sim 29,730 \mathrm{Ci}$

$\rightarrow$ Hence a FCM fuelled PWR would generate about 30,000 Ci of C14 per GWe-y by (n,p)

reactions of N14. This is about 3 orders of magnitude more than the total C14 produced in a standard $\mathrm{UO}_{2}$ fuelled PWR. With N15-enriched nitrogen, the C14 production will be lower. For example, considering enriched nitrogen made up of $90 \% \mathrm{~N} 15$ and $10 \%$ N14, the C14 produced would be divided by 10 . It would still be about 2 orders of magnitude more than the total $\mathrm{C} 14$ produced in a standard $\mathrm{UO}_{2}$ fuelled PWR. Enriched nitrogen made up of $99.9 \%$ N15 and 0.1\% N14 would be necessary to maintain the same level of $\mathrm{C} 14$ produced as that in a standard $\mathrm{UO}_{2}$ fuel.

[B.1] Estimation of Carbon-14 in Nuclear Power Plant Gaseous Effluents, EPRI Report 1021106, (2010) 


\section{Appendix C}

\section{Using molybdenum depleted in Mo-95 in UMo fuel}

From the 2002 International Meeting on Reduced Enrichment for Research and Test Reactors, Bariloche, Argentina, November 3-8, 2002 


\section{Using molybdenum depleted in ${ }^{95} \mathrm{Mo}$ in UMo fuel}

K. Bakker, F. Wijtsma

NRG-Petten, P.O. Box 25, 1755 ZG Petten, The Netherlands.

A. Bos, C. Mol, H. Rakhorst, Urenco Nederland B.V., P.O. Box 158, 7600 AD Almelo, The Netherlands.

M. Bretscher, G. Hofman, J. Snelgrove

Argonne National Laboratory, 9700 South Cass Avenue, Argonne, Il 60439-4815.

\section{$\underline{\text { Introduction }}$}

In recent years significant interest was gained in UMo fuel to be used in Material Test Reactors. This interest was induced by the fact that UMo fuel is mechanically stable, even at high uranium concentrations and high U-burnup. These properties are required in order to use Low Enriched Uranium (LEU) and still be able to achieve high flux and burnup values and, thus, to facilitate the conversion from High Enriched Uranium (HEU) to LEU.

Neutronics computations have shown that, although the Mo concentration in UMo fuel is not very high (about $5-10 \mathrm{w} \%$ ), the neutron absorption cross sections of natural Mo are sufficiently high to have a considerable negative impact on the reactivity of this UMo fuel. In the present research the neutron absorption cross sections of natural Mo are discussed and the option to reduce the cross section of molybdenum by depleting the Mo in ${ }^{95} \mathrm{Mo}$ is described. Finally the economic consequences of using Mo depleted in ${ }^{95} \mathrm{Mo}$ are briefly discussed.

\section{$\underline{\text { Neutronics }}$}

The isotopic composition of natural molybdenum is shown hereafter (Figure 1). It can be remarked that the ${ }^{95}$ Mo content is about $16 \%$ in natural Mo.

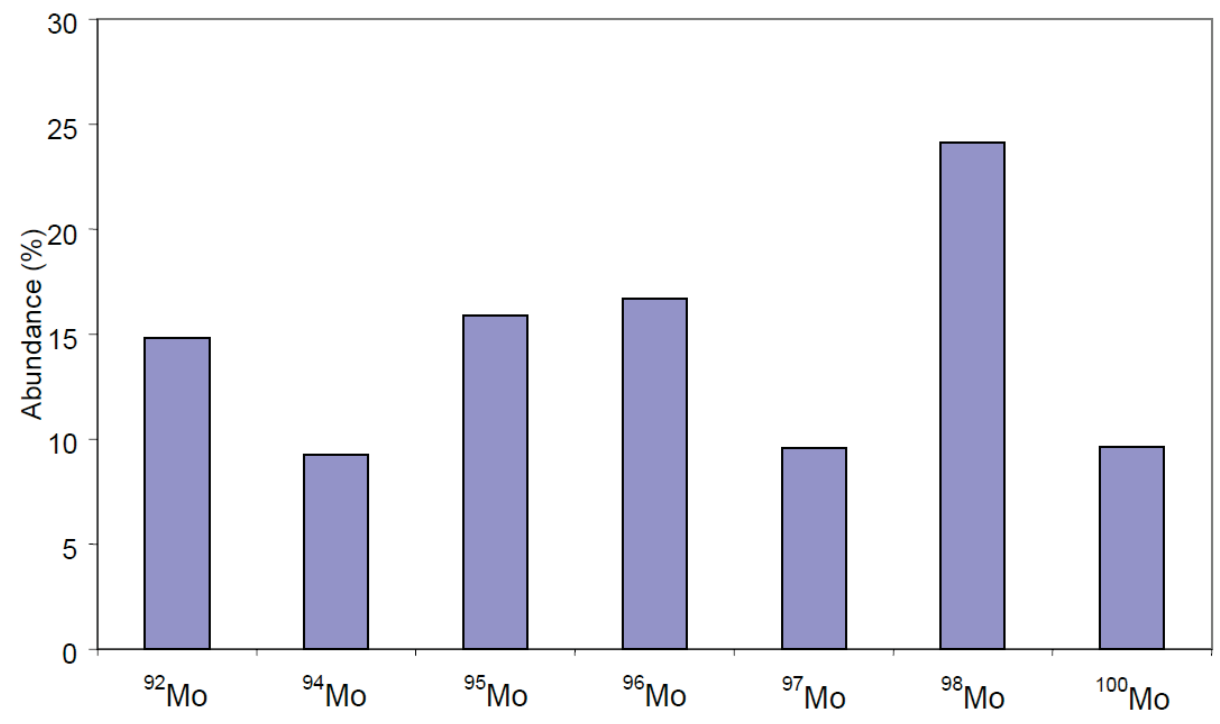

Figure 1 The isotopic composition of natural molybdenum. 
The neutron absorption cross sections for thermal and epi-thermal neutrons are shown for the various Mo-isotopes (Figure 2, Figure 3). The lines marked average give the average cross section values using the isotopic abundance of natural Mo.

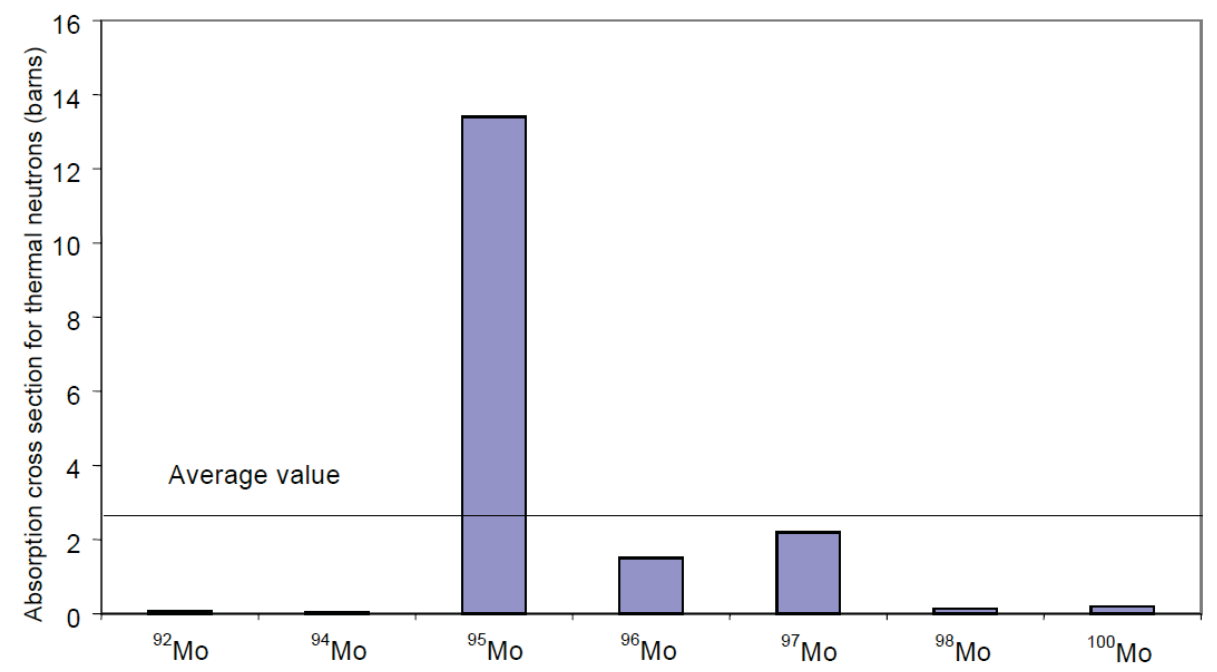

Figure 2 The neutron absorption cross sections for thermal neutrons.

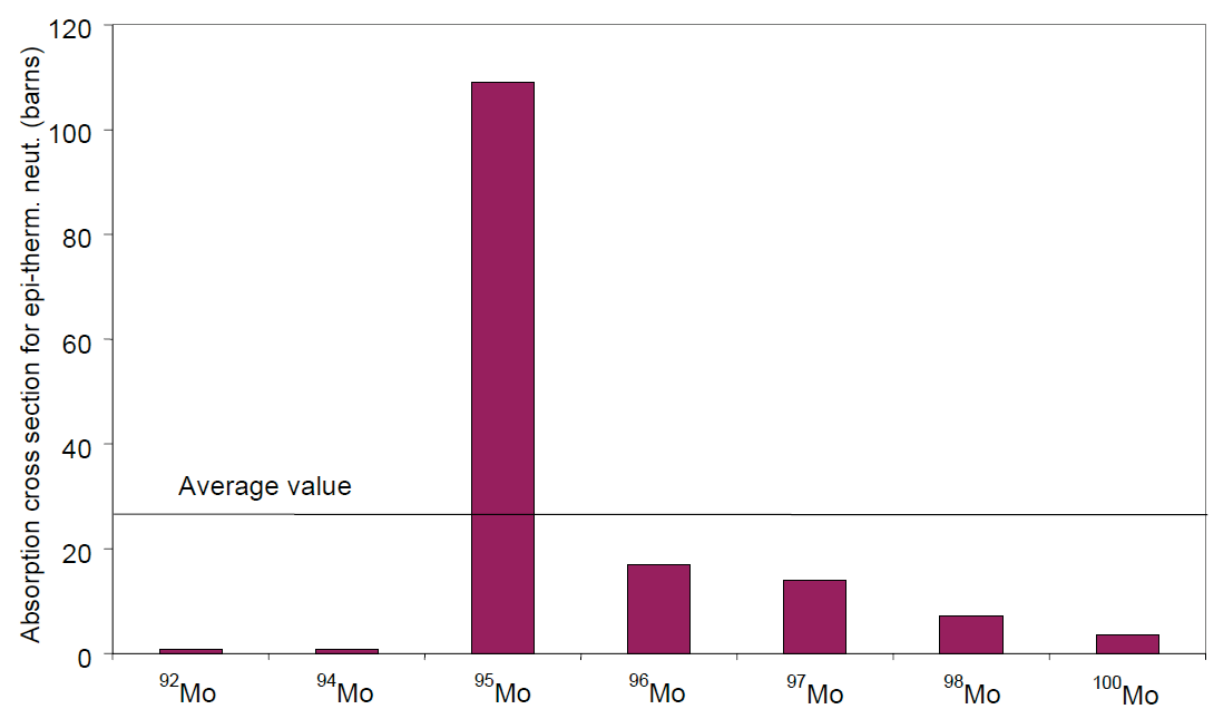

Figure 3 The neutron absorption cross sections for epi-thermal neutrons.

These data show that ${ }^{95}$ Mo has a much larger cross section than the other Mo-isotopes. ${ }^{92}$ Mo and ${ }^{94} \mathrm{Mo}$ have the smallest cross sections, while ${ }^{98} \mathrm{Mo}$ and ${ }^{100} \mathrm{Mo}$ also have small cross sections. Depletion of molybdenum in ${ }^{95} \mathrm{Mo}$ will therefore significantly reduce the neutron absorption cross section, especially in the epi-thermal range. 


\section{${ }^{95}$ Mo depletion}

URENCO has a division in which various types of stable isotopes are enriched. Examples of these stable isotopes are:

- Iridium, enriched in ${ }^{191} \mathrm{Ir}$, which can be used to produce high activity ${ }^{192} \mathrm{Ir}$ radioactive sources.

- Zinc, depleted in ${ }^{64} \mathrm{Zn}$, which is used to decrease the corrosion and decrease the ${ }^{60}$ Co release in the primary system of nuclear power plants.

Enrichment of these stable isotopes is done using ultra-centrifuges (Figure 4).

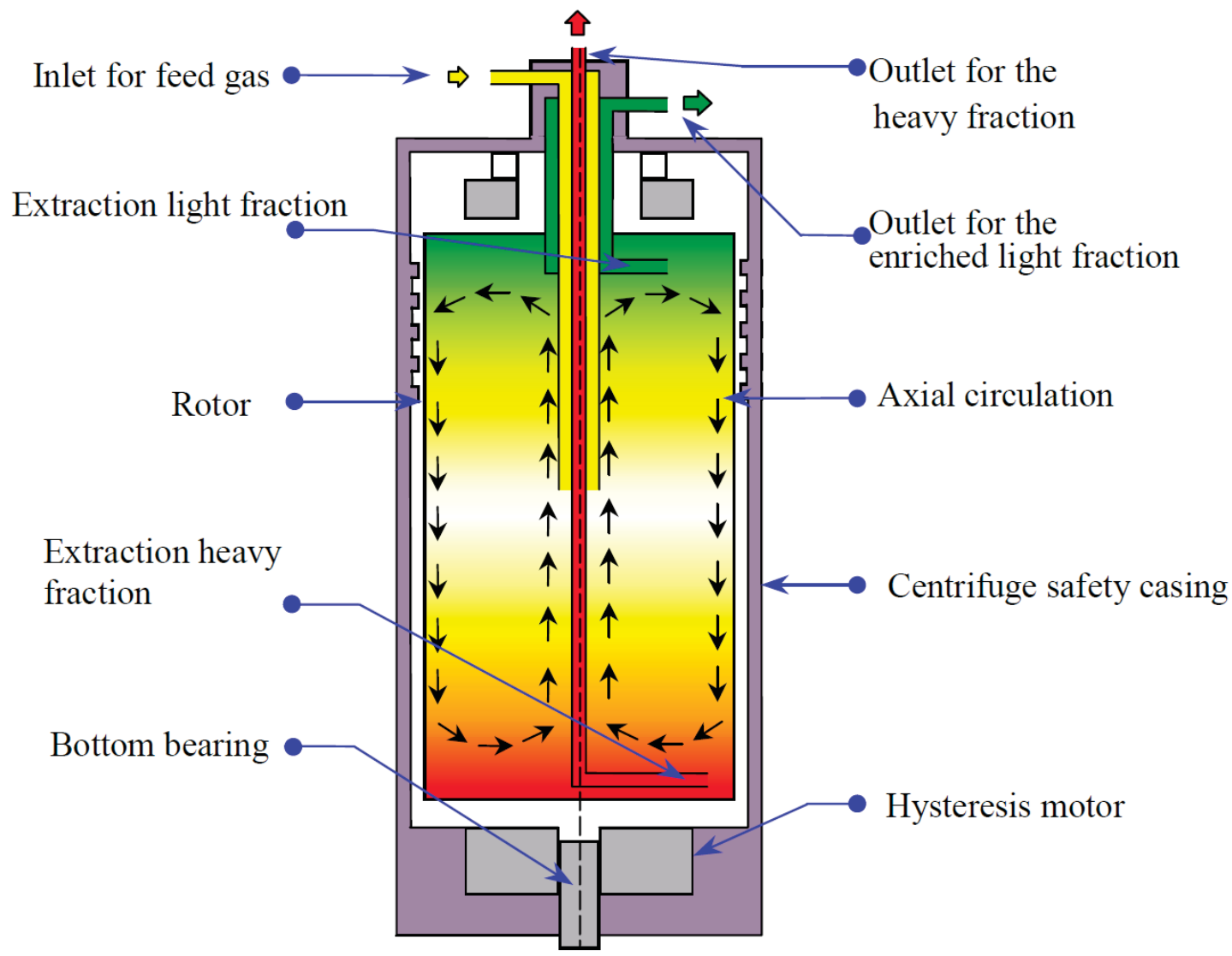

Figure 4 Schematic cross section of an ultra-centrifuge.

URENCO studied the possibility of enriching/depleting molybdenum. Molybdenum appears to be a suitable element for ultra-centrifuge enrichment/depletion using $\mathrm{MoF}_{6}$ as a gaseous compound.

Depletion of Mo in ${ }^{95}$ Mo can either be done by enriching the molybdenum in the light isotopes $\left({ }^{92} \mathrm{Mo}\right.$ and $\left.{ }^{94} \mathrm{Mo}\right)$ or in the heavy isotopes $\left({ }^{98} \mathrm{Mo}\right.$ and $\left.{ }^{100} \mathrm{Mo}\right)$. The isotopic composition after depletion depends on the original (natural) abundance of the various isotopes and the number of depletion steps. Typical isotopic compositions after ${ }^{95} \mathrm{Mo}$ depletion are shown in Figure 6. The total concentration of light isotopes in natural Molybdenum $\left({ }^{92} \mathrm{Mo}\right.$ and $\left.{ }^{94} \mathrm{Mo}\right)$ is smaller than the total concentration of heavy isotopes $\left({ }^{96} \mathrm{Mo},{ }^{97} \mathrm{Mo},{ }^{98} \mathrm{Mo}\right.$ and $\left.{ }^{100} \mathrm{Mo}\right)$. Therefore, the mass fraction of enriched isotopes that can be obtained from enriching light isotopes will be smaller than that 
which can be obtained from enriching heavier isotopes. The average absorption cross sections are reduced by a factor of about 2 when the heavy isotopes are enriched and by a factor of about 3.5 when the light isotopes are enriched.

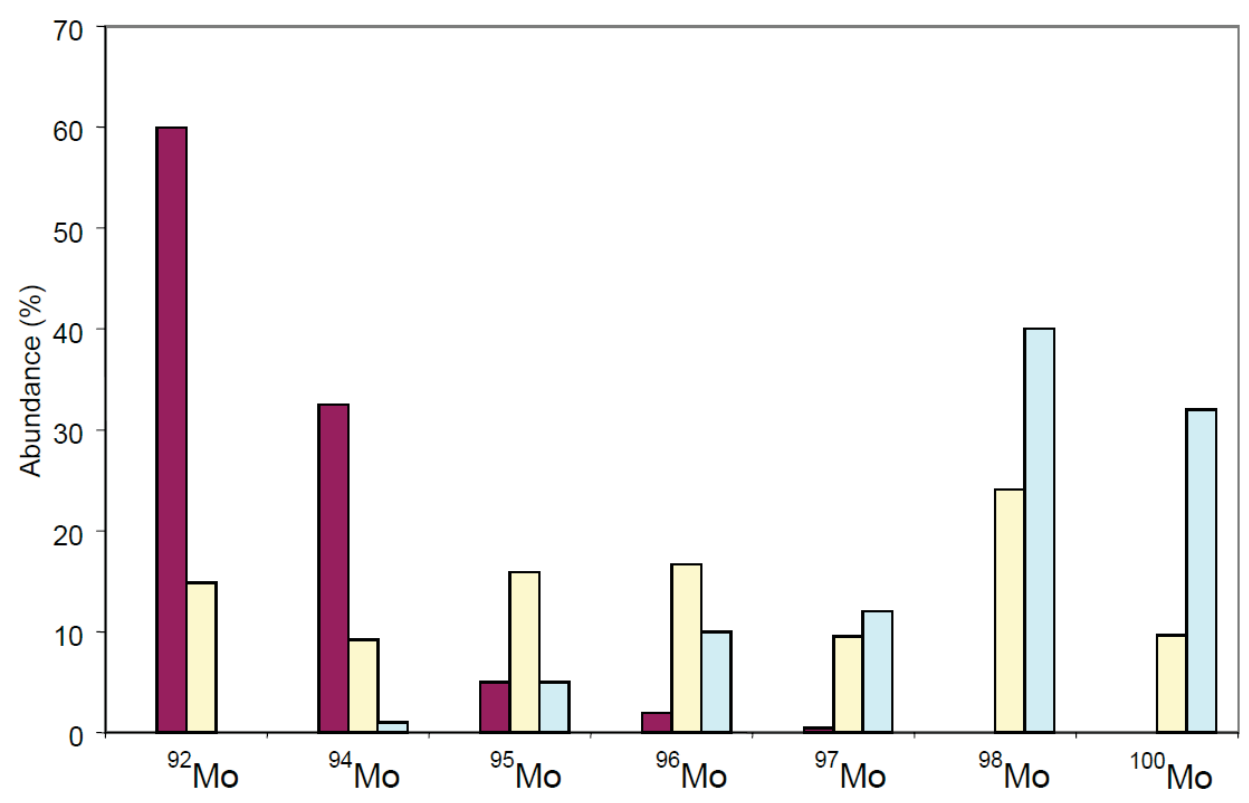

Figure 5 Approximate isotopic compositions after ${ }^{95} \mathrm{Mo}$ depletion. Purple marks the composition after enrichment in the light isotopes. Yellow marks the natural composition. Blue marks the composition after enrichment in the heavy isotopes.

\section{$\underline{\text { Economics }}$}

The advantage of using ${ }^{95}$ Mo depleted Mo in UMo fuel can either be:

- Increasing the cycle length;

- The possibility to use a higher Mo content to enhance the fuel's irradiation stability without too large an impact on reactivity; or

- Decreasing the U content or ${ }^{235} \mathrm{U}$-enrichment.

The exact advantage will be Material Test Reactor specific.

The neutronics computations show that decreasing the ${ }^{95} \mathrm{Mo}$-content from $16 \%$ to $5 \%$ can yield an increase of the cycle length of about 4 or $6 \%$ for a typical medium-power Material Test Reactor when the heavy or light Mo isotopes, respectively, are enriched. The exact cycle length increase depends however on many parameters such as:

- Maximum burnup;

- Ratio U/Mo; and

- Reactor geometry.

An economic assessment showed that using ${ }^{95} \mathrm{Mo}$ depleted Mo is an interesting option for UMo fuel. 